\title{
1 An innovative generic platform to simulate real- 2 time PTO damping forces for ocean energy 3 converters based on SIL method
}

\author{
Xue Jiang ${ }^{1}$, Sandy Day ${ }^{1}$, David Clelland ${ }^{1}$ \\ 1: Dept. of Naval Architecture, Ocean and Marine Engineering, University of Strathclyde, Henry Dyer \\ Building, Glasgow, G4 OLZ, UK
}

\begin{abstract}
This paper proposes a generic PTO (power-take-off) simulation platform which can be used to predict how devices perform in wave conditions when a simulated real-time linear or non-linear PTO damping forces is employed. The experimental platform could be used to investigate the maximum power output of wave converters(WECs) without constructing a physical PTO system and complex control strategies at the design stage of a WEC, thus making it efficient and inexpensive to explore different PTO solutions. For this purpose, a software-in-the-loop (SIL) simulation method is adopted which uses an innovative control loop running on an inexpensive real-time controller coupled to a DC motor which simulates the PTO damping torque. To calibrate the proposed PTO simulation platform, 1349 drop tests are carried out. A series of relationship curves and corresponding equations are drawn for both the linear and non-linear PTO cases. Moreover, correlation curves for input gains and the produced damping force coefficients are provided. The correlation indicates the PTO simulation platform's capacity of simulating linear PTO can reach 40-220 and can reach 10-70 for quadratic damping in terms of damping force coefficient. To investigate the accuracy of the platform, uncertainty analyses are also carried out in good details. The calibrating tests and uncertainty analyses indicate that the proposed experimental platform can be used to overcome many of the limitations in modelling PTO systems at laboratory scale to simulate both real-time linear and quadratic PTO damping forces.
\end{abstract}

Keywords: Ocean energy, Experimental platform, SIL simulation, PTO damping, Uncertainty analyses Highlights:

$>$ An innovative generic platform used to produce a range of both linear and quadratic realtime PTO forces is presented;

$>$ The performance of the platform is investigated using multiple calibrating drop tests.

$>$ Reasonable correlation curves between the input gains of the PTO simulation platform and the coefficients of simulated PTO damping forces are achieved for both linear and quadratic cases.

$>$ The correlation indicates the PTO simulation platform's capacity of simulating linear PTO can reach 40-220 and can reach 10-70 for quadratic damping regarding damping force coefficient.

$>$ Considering the application of this platform in model testing, the uncertainty of the platform is analysed in good details.

\section{Introduction}

Being consistent day and night, ocean waves are a more promising resource carrying a higher energy density compared to solar and wind, as shown in Fig.1. If successfully exploited, wave energy, will make a significant contribution to meeting global energy demands while reducing the negative impact on climate change and environmental pollution, by reducing the rate of consumption of fossil fuels. 


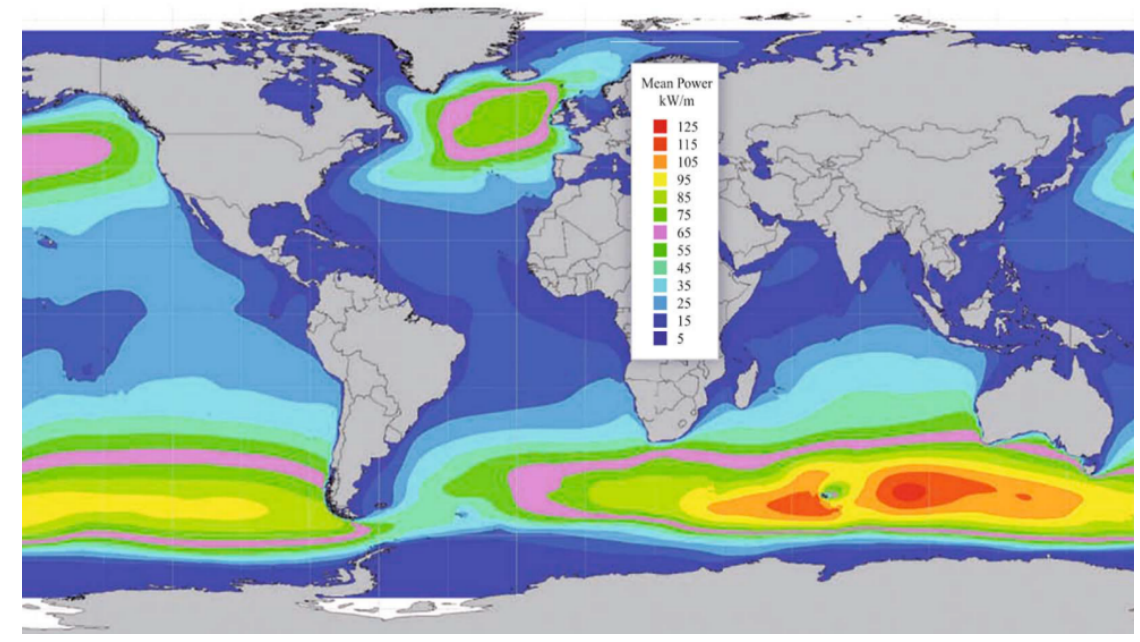

Figure 1 Global distribution of mean wave power density in $\mathrm{kW} / \mathrm{m}[1]$

47 However, there are not enough commercial grid-connected Wave Energy Converters (WEC's) installed at this moment, and only a few megawatts are installed. According to the World Energy Council, stateof-the-art wave energy technologies operate at an LCOE (Levelized Cost of Energy) of 49.6 cents or 38.9 pence per $\mathrm{kWh}[2-5]$, which is above average standards of 10-13pence per kWh and still going upward. Recently a growing number companies who initially had a considerable interest in wave energy utilisation are investing elsewhere or having growing financial difficulties due to a combination of high up-front development and capital costs, underperforming prototype devices together with underestimating the inherent technical challenges connected to the harsh ocean environment. For example, in 2013, Voith Hydro decided to shut down WaveGen who developed the LIMPET power station. One year later, the Pelamis went burst. The Aquamarine Ltd which developed the Oyster device stopped their business in November 2015.

As demonstrated in[6], the economic feasibility of a wave energy converter depends mostly on its power take-off system, maximising the output power and significantly increasing the reliability of WEC PTO systems may be the most promising way to minimise the LCOE. Therefore it is necessary to consider the PTO regarding the accurate testing of wave energy converter devices. There existing a few well known PTO solutions employing hydraulic systems, turbines, and linear generators, as shown in Fig.2[7]. However, it is almost impossible for correctly model a PTO system regarding the exact amount of desired damping torque. Therefore, if simplify the linear and non-linear PTO systems into linear and non-linear damping, it becomes available to simulate the PTO by any scales.

Nowadays ocean energy developers are more aware of the need to increase device reliability and performance while reducing costs. Accurate testing of devices before deployment is even more crucial - an aspect which is the motivation for this paper. However, most researchers performed experiments with an orifice plate representing the PTO in CFD simulation or without considering the damping effect induced by the PTO system. For instance, Sykes et al.[8] investigated the hydrodynamic performance of a Fixed type axis Symmetry Cylindrical Oscillating water column device using a boundary element model WAMIT without considering the damping effect induced by the PTO system. Additionally, for testing concerning the PTO, people only able to simulate quite limited linear damping using air or other dampers, due to the absence of a suitable PTO simulation method. 


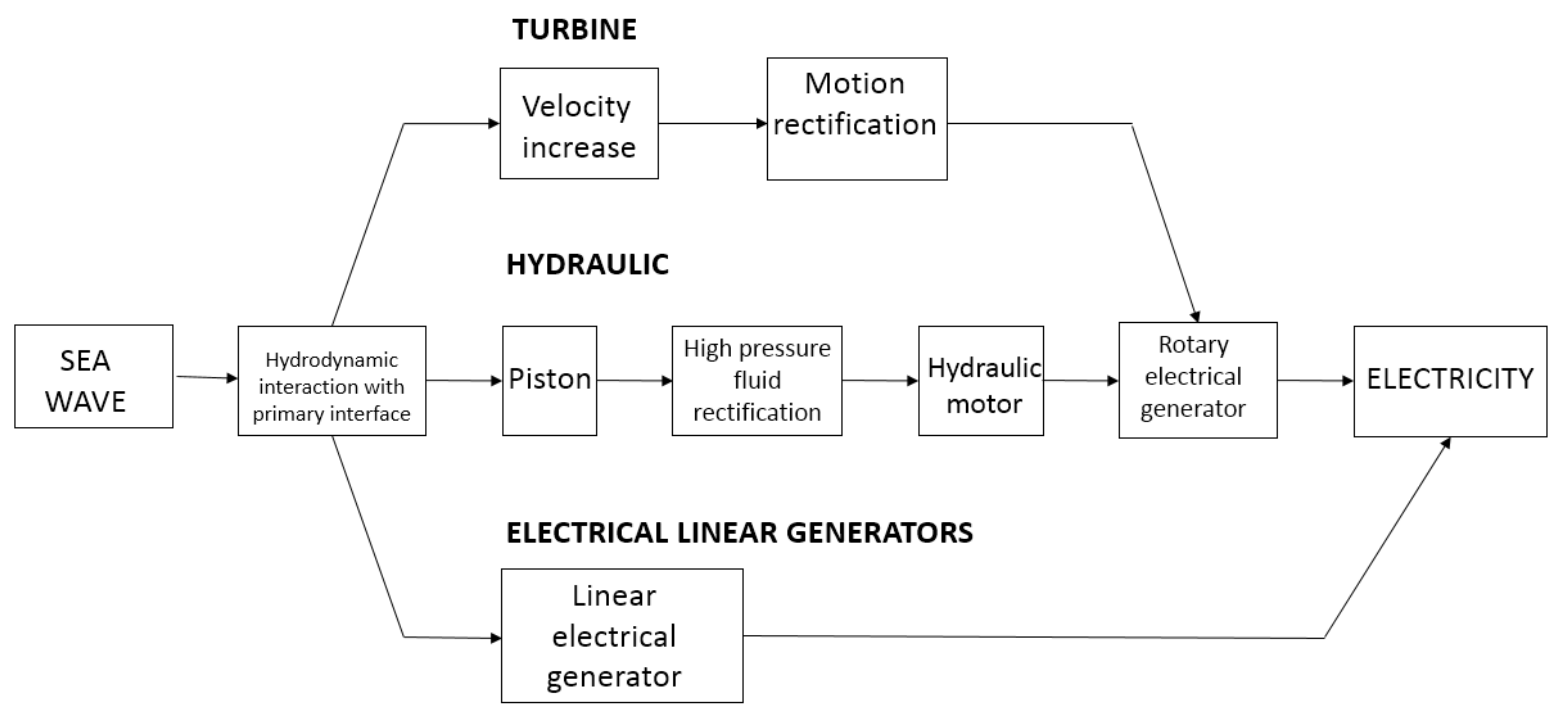

Figure 2 Alternative PTO mechanisms [7]

Therefore, motivated by the need to meet the accurate testing of devices before deployment, this study is aimed at developing a low-cost innovative PTO simulation platform which can be used to test how wave converters perform when a simulated linear or non-linear PTO damping is employed. Thus making it possible to reach an optimal design for different WEC/PTO combinations at the testing stage. Moreover, by changing the input gains of the PTO simulation platform, different PTO strategies are simulated. After proposing a novel PTO simulation platform, a $40^{\text {th }}$ scaled Oyster device is applied on this platform, and numerous tank tests in both regular and irregular waves with linear or nonlinear PTO damping strategies are carried out. And details are provided in the companion paper "Hydrodynamic responses and power efficiency analyses of the oscillating wave surge converters with different simulated PTO strategies". However, it is fundamental to explain how this PTO simulation platform works and how accurate it is instead of just showing the tank testing results and the power efficiency analyses. Considering it will be almost 20000 words and it will be too complicated to explain everything in one paper, two articles are written. And this paper is one of the two articles, which proposed an innovative PTO simulation approach and enable the future hydrodynamic performance and power efficiency analyses of a scaled Oyster device model under a large number of different PTO strategies.

This paper is organised as follows: In section 2, a literature review of the state-of-the-art wave energy technologies is given and the challenges and limitations are addressed. Section 3 presents the working principle of PTO simulation based on SIL method and its construction. In Section 4, the key input parameters and the results of the calibrating tests are discussed. ? Reasonable correlation curves between the input gains of the PTO simulation platform and the coefficients of simulated PTO damping forces are achieved for both linear and quadratic cases. Moreover, The correlation indicates the PTO simulation platform's capacity of simulating linear PTO can reach 40-220 and can reach 10-70 for quadratic damping regarding damping force coefficient.The uncertainty analyses are provided in section5. Section 6 summarises the conclusions from the study.

\section{Literature Review}

Numerous wave energy extraction techniques have been proposed over the past two centuries. The history of attempts to harness wave energy is divided into three time periods as the authors concluded in this paper, to summarise past achievements. From 1799 to 1990 although more than one thousand patents were registered, the activity of converting wave energy remained mainly at the academic level[9-15]. From 1990 to 2011, prototype wave energy converters aimed at large-scale energy 
production were deployed worldwide with activities and interest on a steep upward trend[16-20]. From 2011 up to the present, the number of the prototype being implemented continues on a downward trend with fewer countries reporting developers who are actively advancing their technologies toward commercialisation or have achieved a significant amount of milestones along that path[21-24] (Fig.3.). Liliana et al. reviewed the performance of various state-of-the-art wave energy converters and concluded the most existing WEC devices are still at the Research \& Development (R\&D) stage, and the well-known Pelamis system is currently encountering financial problems[23].

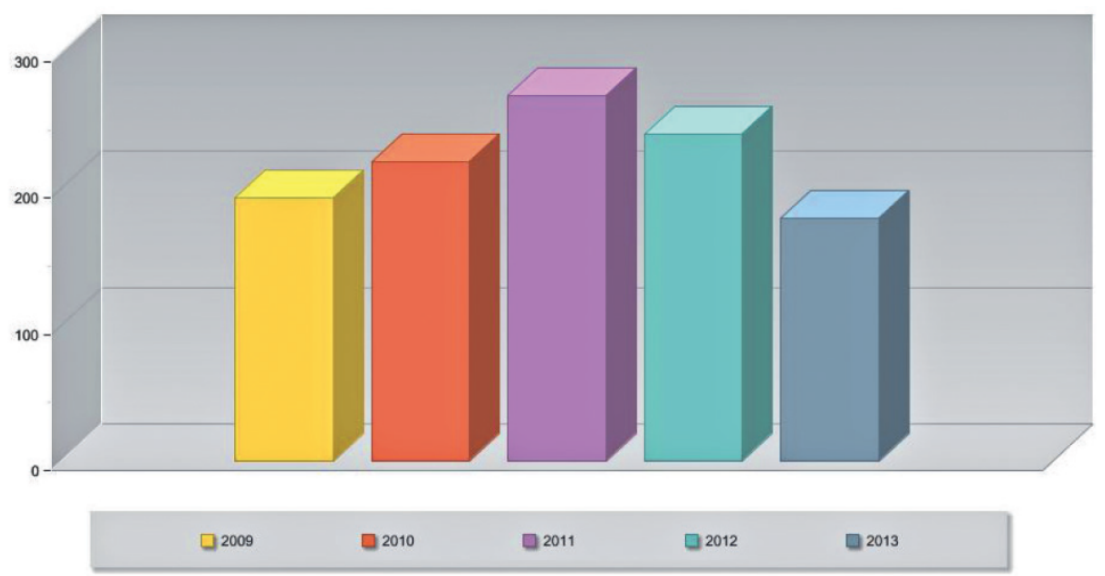

Indeed, we have seen a growing trend in exploring better control strategies to maximise the output power of WECs, so as to rescue the immaturity of this industry. For example, J.C.C. Henriques et al. developed a PTO control of an oscillating-water-column spar-buoy wave energy converter, and hardware-in-the-loop simulation is used in experiments to characterise the proposed control algorithms[25]; Jorgen Hals et al. proposed model-predictive controller to exploit the full absorption potential of wave-energy converters; N.M. Tom et al. used the Pseudo-spectral control which allows optimising the controller design to achieve the optimisation of the output power of an oscillating surge WEC. Other exploration of control strategy could be seen in[26] electrical control, adaptive control in[27], phase control in [28]. However, those control strategies can only very limitedly improve the performance of the device, and further validation testing still requires the absence of a proper PTO simulation in the Lab.

On the other hand, numerical simulation prospers due to the convenience to consider the WEC system as a fully-coupled system, in which the PTO is usually oversimplified and modelled. For example, David I.M. Forehand et al. proposed a fully coupled Wave-to-Wire Model of an array of wave energy converters, to explore the power conversion in Matlab, where a hydraulic PTO simplified and modelled [29]. Moreover, the hydraulic power take-off system initially proposed by R Henderson recommended for Pelamis in [30]. Indeed the hydraulic PTO system stands out among other solutions(turbines, electrical, and linear generators)because of the merits of good robustness, speed control, energy storage. However, the Pelamis project is facing severe financial difficulties. The authors believe it is necessary to explore the best PTO efficiency before the deployment of any real PTO system to maximise the investment. We get inspiration to simulate the PTO damping by the SIL method to enable the real-time experiments with a correspondingly scaled or full-scale simulated PTO. For more details about SIL simulation see references[31, 32]. 
Current testing concerning a PTO system for WECs only involves in minimal linear PTO damping force, which is usually provided by very simple damping actuators. For example, Zhipeng et al. conducted a series of model tests for a heaving-buoy wave energy converter using various air dampers to simulate the PTO damping[33], Richard et al.[34] reviewed how a linear generator can be used as a power takeoff unit to apply a damping force. However, this method only can represent some linear generators, and in many cases, the PTO system produced nonlinear damping. The non-linear PTO currently is only considered in a study based on numerical modelling. Facing the limitations of the absence of a PTO system, the authors believe a generic way is required to simulate the PTO damping to enable various testing with a proper simulated PTO damping for the wave energy conversion device, at the design and optimisation stage.

By the way, a recent proposal to harvest ocean energy by new triboelectric Nanogenerator networks was published in nature[35], which attracted a lot of attention, however, as demonstrated in [36-38], this exciting technology is still at the theoretical stage.

\section{Development of the platform}

It is necessary to evaluate the amount of energy that a device can extract from sea conditions, before investing a significant amount of money into PTO development. People find some simplified ways to model a PTO for a WEC device, as reviewed in section 2. In this section, the SIL method is innovatively adapted to achieve PTO damping in real-time. And calibration testing is designed to provide the validity of the technique. Therefore, if the reader can not thoroughly understand the working principle from this section due to the innovative use of the software-in-the-loop application, part 4 may be helpful to explain further how different strategies are implemented by the proposed method, enabling the platform to simulate a range of linear damping and quadratic damping for the PTO damping.

\subsection{The Damping Force of PTO}

The definitions of PTO and damping force for a WEC are described in[30] as:

'The extraction, by any wave energy converter (WEC), of useful energy from ocean waves requires that the waves apply force to some form of responsive mechanism able to resist the working force that the waves apply, and some form of reference against which that mechanismcan react. The mechanism by which energy is transferred between the waves and the WEC, and subsequently or directly into useful form, is generally known as the power take-off (PTO).'

As stated above, when a PTO system draws electrical power from a WEC, a damping torque is applied to the device. Thus, if there is an approach to duplicate the real-time damping force appropriately to follow a particular linear or nonlinear function, then it is assumed in this paper that a linea or nonlinear damping strategy is available to duplicate. Moreover, the authors simplify the linear or linear PTO system into a linear or nonlinear damping force function. Then an electric motor is used to produce the real-time damping force following the control function which represents the PTO strategy.

\subsection{Working principal}

The PTO simulation platform is based on the SIL method, so the primary principle is about explaining how to make the software and the loop to produce the aimed PTO damping. As we mentioned above, a DC motor is designed to deliver the PTO damping, and the software (whose control function is the reflect of the aimed damping function) in the loop controls the motor to provide a linear or quadratic damping. As shown in Fig.4, the loop consists a National Instruments "MyRio" controller, a power 
amplifier (A), a DC motor( PML GR12CH motor combined with brake, tacho and encoder) (M), an method of applying a known torque to the motor shaft (falling mass on the worm drive, which is also the method we used in calibration testing), a tachometer(T) and the software in the computer linked to "MyRio" controller. A separate Data Acquisition System (DAQ) is used to record data including the current signal from the resistive current sensor(R), and velocity signals in real time. When the mass released, it will carry a downward acceleration due to gravity; then the speed will be captured by the tachometer and read by the "MyRio" controller. The controller software will calculate a signal proportional to the input velocity to command the motor produce a torque resisting that of the falling mass. The controller loop is running fast in real time, and the system will finally reach an equilibrium state when both the velocity of the mass and the damping torque reach an equilibrium state. Measurements from a typical test are shown in Fig.5, which can be classified into four distinct periods. During period $A$, the mass is at rest, $1.5 \mathrm{~m}$ above the final point. Period $\mathrm{B}$ is the acceleration period of the mass after release and period $C$ is the equilibrium state. In period $D$, the mass has travelled $1.3 \mathrm{~m}$ and reaches its final point.

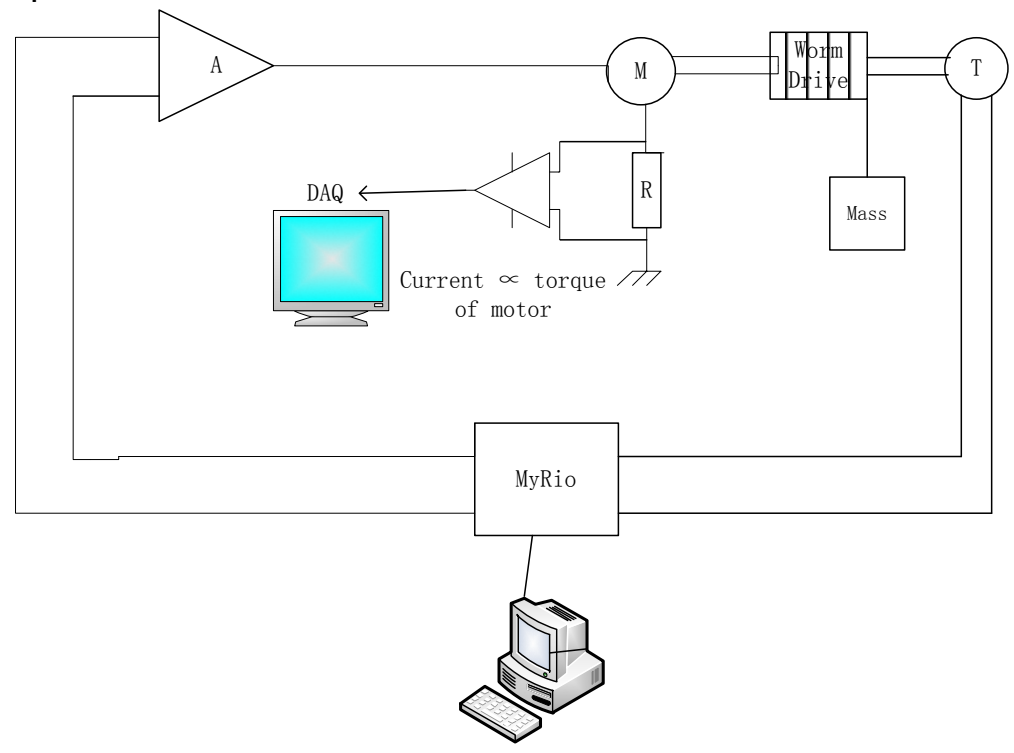

Figure 4 Schematic diagram of the loop for simulating the PTO damping

And according to Newton's second law and third law, each damping torque triggered by the dropping mass should be as follows.

$F_{\text {damping }}=$ weight $=m \times g$

$T_{\text {dampings }}=F_{\text {damping }} \times d / 2$

where $F_{\text {damping }}$ stands for the damping force, $T_{\text {dampings }}$ stands for the damping torque produced by the motor, $d$ is the diameter of the worm drive connected to the output shaft of the DC motor.

A current sensor is designed in the loop to measure the current of the DC motor to give a prediction on the dynamic damping torque $\left(T_{\text {damping } D}\right)$ according to the proportional relationship between the current and torque for a DC motor. However the proportional relationship will be slightly affected by the properties of the motor itself and environmental factors, e.g. motor temperature, so the comparisons between the two damping torques $\left(T_{\text {dampings }} \& T_{\text {damping } D}\right)$ will be discussed in Section 4.4 as part of the uncertainty analysis of the platform. 
The damping function in the program is described as

$F(t)=\frac{\text { gain }}{100} \dot{y}(t)^{n}$

where the gain/100 is a user-supplied scaling factor, $F(t)$ is the damping force, and $\dot{y}(t)$ is the velocity, which is the derivative of the displacement $y(t)$ concerning time $t$. When " $n=1$ ", the platform will simulate a real-time linear PTO damping force, similarly when " $n=2$ ", the platform will simulate a real-time quadratic damping force. And the targeted damping equation is described as $F(t)=\varsigma_{P} \times \dot{y}(t)^{n}$

where $\varsigma_{P}$ represents the coefficient of the real-time PTO damping force.

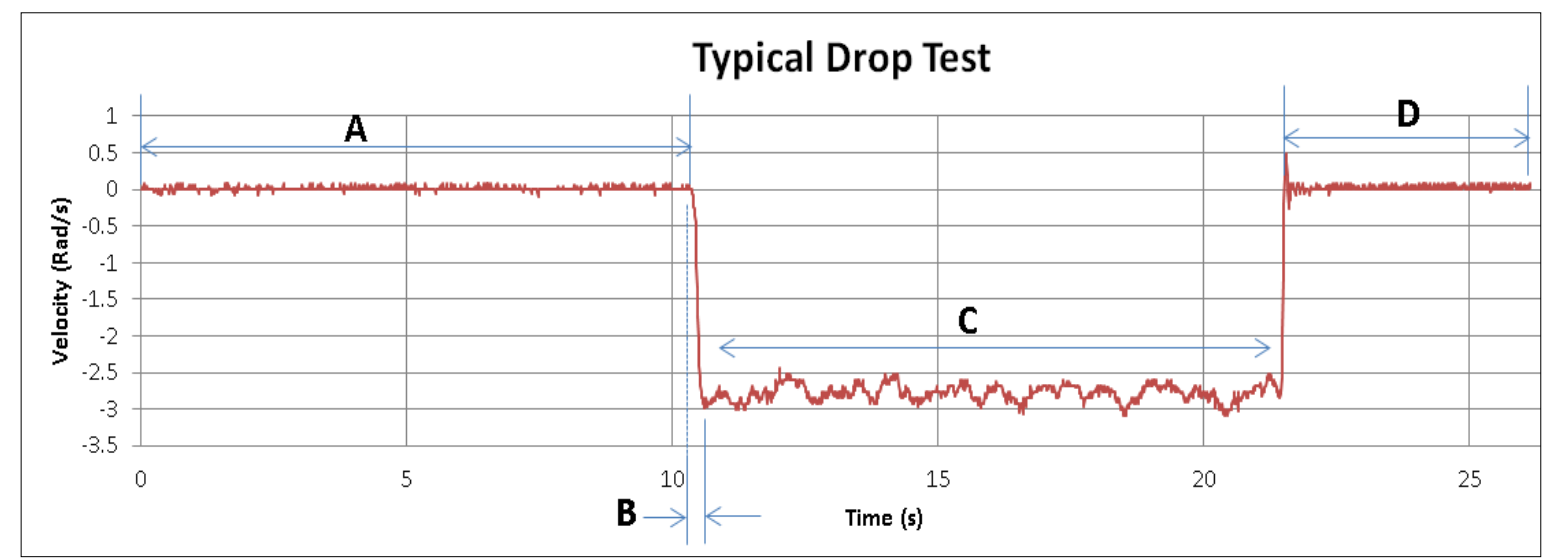

Figure 5 A typical drop test monitored by DAQ

The idea of using drop tests to calibrate the system is that: by one standard drop test, it is calibrated that the motor produced damping equal to the mass damping, at the meantime a corresponding velocity for that damping value is marked. For the real-time experiments in labs the trigger is not a driving mass, instead is the speed of a specific WEC model. By quite a few calibrating drop tests using increasing mass, it can observe if a linear or quadratic damping is achieved as predefined by the control function in the software in the loop. By changing the input gains, it can observe through following drop tests if the PTO damping with different coefficients is achieved.

\subsection{Construction of the platform}

To enable the running of the SIL application, some simple electrical equipment is used to form a monitoring and executive platform as shown in Fig.6. The machines allow the motor to produce the damping force according to the control function in the software simultaneously enable the authors to monitor and record the histories of torque, position and velocity. As shown in Fig. 6, the electronic part of the PTO testing platform is made up of five main components: a GR12CH printed armature DC motor fitted with a tachometer and a position encoder, a DC servo amplifier, National Instruments MyRIO-1900 controller, MICRO 1401 II data acquisition (DAQ) system, and a high-accuracy current sensor equipped with current shunt monitor. 


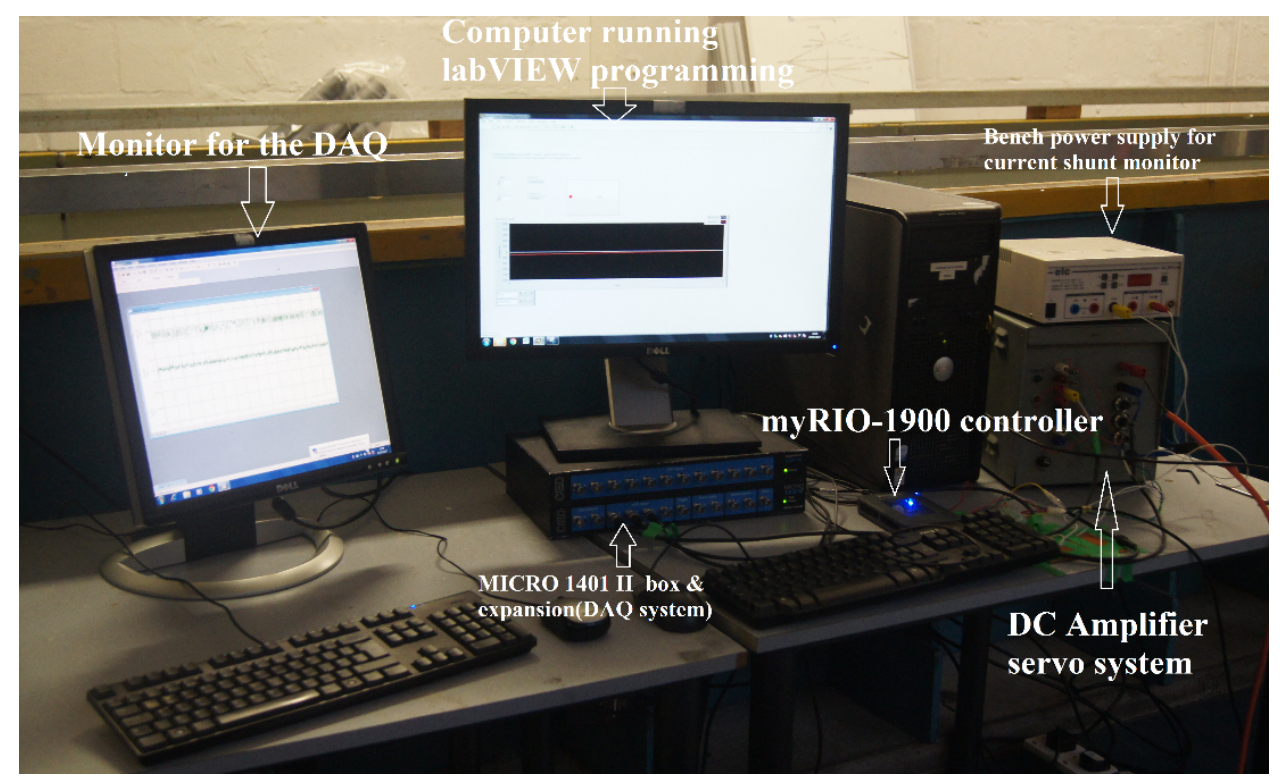

Figure 6 Components of the PTO damping simulation platform

258 To investigate the validity and characterise this platform, 1349 drop tests are carried out. And the 259 input gains for the control function in software as well as weights of dropping mass used to trigger the 260 actuating motor is carefully selected as follows.

\subsection{Selection of the input gains and driving masses}

To characterize the PTO platform, different values of the input gains of the PTO simulation platform are carefully selected to assure the tests are located in a reasonable combined range of all the instruments adopted (refer to Fig.6). Table 1 lists the selected gain being observed during the calibrating tests. Six gain values were selected to achieve six linear damping coefficients and five gain values to obtain the five nonlinear damping coefficients. The input gain is for the control function of the software used in the loop.

Table 1 Selected gains for drop tests

\begin{tabular}{llllllll}
\hline & $\begin{array}{l}\text { Available Gain } \\
\text { range }\end{array}$ & Gain1 & Gain2 & Gain3 & Gain4 & Gain5 & Gain6 \\
\hline $\mathrm{n}=1$ & $20-120$ & 20 & 40 & 60 & 80 & 100 & 120 \\
$\mathrm{n}=2$ & $40-200$ & 40 & 80 & 120 & 160 & 200 & - \\
\hline
\end{tabular}

As mentioned in section 3.2, a series of weights/mass (as shown in Table 2) are used to trigger the SIL application, and a set of experiments are carried out to validate each specific damping coefficient. For each drop test, the static damping torque $\left(T_{\text {dampings }}\right)$ is obtained by equation 1 and equation 2 , but also the current measurement is monitored and recorded as a prediction of dynamic damping torque produced by the motor. For the linear case 14 weight values in the range, $0.3-1.6 \mathrm{~kg}$ were used, while for the nonlinear instance the range was $0.4-1.6 \mathrm{~kg}$. To investigate the uncertainty, each drop test is repeated three times for each weight and each gain. The averaged value obtained from the repeat test is used to observe the produced damping.

\begin{tabular}{lllllll}
\hline M1 & M2 & M3 & M4 & M5 & M6 & M7 \\
\hline
\end{tabular}




\begin{tabular}{cccccccc}
\hline $\mathrm{n}=1$ & - & 0.4 & 0.5 & 0.6 & 0.7 & 0.8 & 0.9 \\
$\mathrm{n}=2$ & 0.3 & 0.4 & 0.5 & 0.6 & 0.7 & 0.8 & 0.9 \\
\hline $\mathrm{n}=1$ & 1 & 1.1 & 1.2 & 1.3 & 1.4 & 1.5 & 1.6 \\
$\mathrm{n}=2$ & 1 & 1.1 & 1.2 & 1.3 & 1.4 & 1.5 & 1 \\
\hline
\end{tabular}

The mechanical model of the PTO Testing Platform used in the calibrating tests comprises an aluminium mounting frame, a DC motor, a worm drive, $3 \mathrm{~mm}$ multi-stranded steel transmission wire and two weight pans, as shown in Fig.7(b). For all of the drop tests, wire pretension is applied using two $0.1 \mathrm{~kg}$ masses -"m", as shown in Fig.7(a), to hold the wire on the worm and also to ensure a minimum tension in the multi-strand wire to minimise the initial wire 'stretch'. The mass $M$ is used to drive the wire to produce an input speed, and all weights selected to use are listed above. Details of the mechanical experimental set-up are as shown in Table 3.

(a)

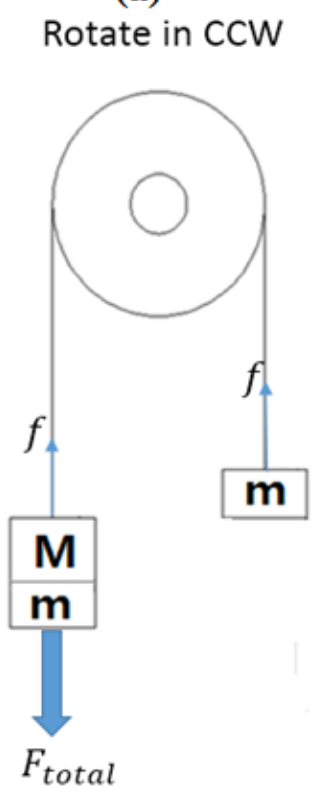

(b)

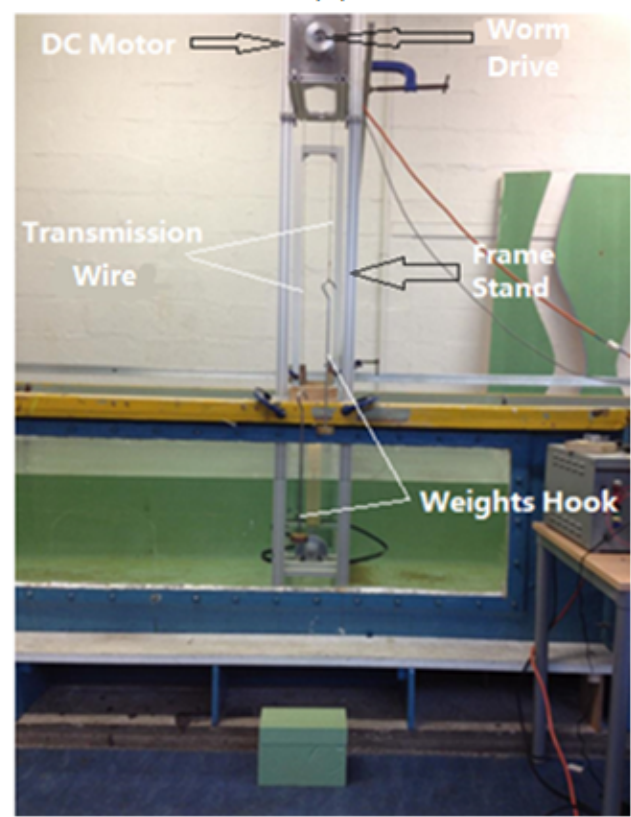

Figure 7 a)Schematic diagram of pretension in drop tests in counterclockwise, $f$ is the pre-tension caused by " $\mathrm{m}$ ", and $F_{\text {total }}$ is the driving force caused by " $M$ "; b) Mechanical model of drop

Table 3 Details of mechanical experimental set-up

\begin{tabular}{ccc}
\hline Component & Parameters & Dimension \\
\hline Frame Stand & Total height & $2.1 \mathrm{~m}$ \\
& Total width & $1.6 \mathrm{~m}$
\end{tabular}




\begin{tabular}{ccc} 
Transmission wire & Total length & $1.8 \mathrm{~m}$ \\
& Drop distance & $1.3 \mathrm{~m}$ \\
Hook & Diameter & $3 \mathrm{~mm}$ \\
Worm drive & Weight & $0.1 \mathrm{~kg}$ \\
\hline
\end{tabular}

296

\subsection{Analytical method and results discussion}

In this section, we investigate how the damping torque behaves when different weights are used to drive the PTO simulation platform under different input gains of the linear or quadratic control function.

\subsubsection{Linear PTO control functions $(n=1)$}

Under the linear control function in the software in the loop, the relationship between velocity (V) and the damping torque $T_{\text {dampings }}$ ( the definition of $T_{\text {dampings }}$ seeing section 3.2) are shown in Fig.8, in which each point comes from the average values of the three repeated drop tests. Data points located in the positive torque region represent the drop tests in a counter-clockwise (CCW) direction, which means for those drop tests, each time a specific weight is applied on the worm to drive the motor to rotate in the CCW direction as shown in Fig.7(a). Similarly, the points located in the negative torque region are the results of drop tests in a clockwise direction. Different gain values are indicated by the colour of the star points, black representing the lowest gain value and pink representing the highest gain value. All the input gains used to run the control function is listed above in Table 3.

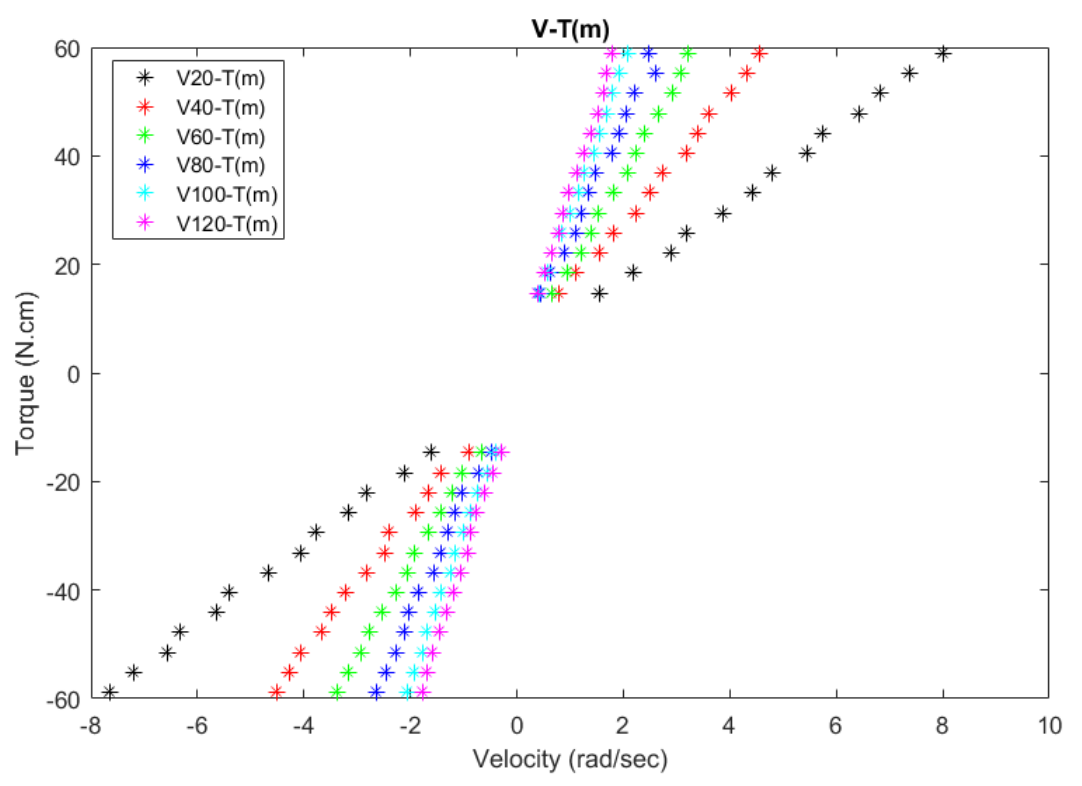

Figure 8 Relationship of velocity and damping torque $\left(T_{\text {dampings }}\right)$ ( the points located in )

As shown in Fig.8, a linear relationship between torque and velocity for each of the different gain value is achieved, and as we increase the input gains for the PTO simulation platform, the slopes of the linear damping increase as well. As gain increases, the slope of the lines increases, which represents a larger damping coefficient. Then each equation is drawn from each group of linear data. Moreover, the damping coefficient $\varsigma_{P}$ can be derived from the fitted equation in Table 4. The fitted equations are in the form of $F(t)=\varsigma_{P} \times \dot{y}(t)+u$, in which the $u$ is the uncertainty of the linear PTO simulation discussed below in section 5 . In this study, six different gain values for linear damping cases were 


\begin{tabular}{|c|c|c|}
\hline \multirow[t]{2}{*}{ Gain } & \multicolumn{2}{|c|}{ Fitted damping equation } \\
\hline & $\mathrm{CCW}$ & $\mathrm{CW}$ \\
\hline 20 & $F(\mathrm{t})=44.22 \dot{y}(t)+2.834$ & $F(t)=46.12 \dot{y}(t)-2.425$ \\
\hline 40 & $F(t)=73.66 \dot{y}(t)+4.585$ & $F(t)=77.57 \dot{y}(t)-1.933$ \\
\hline 60 & $F(t)=107.9 \dot{y}(t)+2.277$ & $F(t)=105.6 \dot{y}(t)-1.909$ \\
\hline 80 & $F(t)=129.5 \dot{y}(t)+4.934$ & $F(t)=133.4 \dot{y}(t)-2.571$ \\
\hline 100 & $F(t)=167.2 \dot{y}(t)+3.445$ & $F(t)=169.9 \dot{y}(t)-2.925$ \\
\hline 120 & $F(t)=194.6 \dot{y}(t)+2.003$ & $F(t)=191.2 \dot{y}(t)-4.143$ \\
\hline
\end{tabular}

examined and the damping coefficients were measured at gain $=20,40,60,80,100,120$, with the corresponding damping ratios $\varsigma_{P}=44.22,73.66,107.9,129.5,167.2,194.6$ in counterclockwise direction and $\varsigma_{P}=46.12,77.57,105.6,133.4,169.9,191.2$, respectively as shown in Table 4.

Table 4 Table of fitted functions based on $T_{\text {dampingS }}$ for linear PTO
326

327

In dynamic model testing, the $T_{\text {damping } D}$ ( the definition of $T_{\text {dampingD }}$ see section 3.2 ) is directly monitored and used to give a prediction of PTO damping instead of $T_{\text {dampings }}$. Therefore relationship curves between $T_{\text {dampingD }}$ and real-time instantaneous velocities are obtained as well. It is seen from Fig.9; the linear damping is assured though it may result in an absolute uncertainty. Therefore, the fitted equations for the six groups of ballpoints in Fig.9. are also obtained. And the corresponding damping ratios are $\varsigma_{P}=45.24,76.4,112.7,139,176.9,206.5$, in counterclockwise direction and $\varsigma_{P}$ $=47.57,80.25,111.9,141.7,179.7,203.1$, respectively as shown in Table 5. Then the uncertainty in methodology is reflected in the difference of $\varsigma_{P}$, which is discussed in section 5 . 


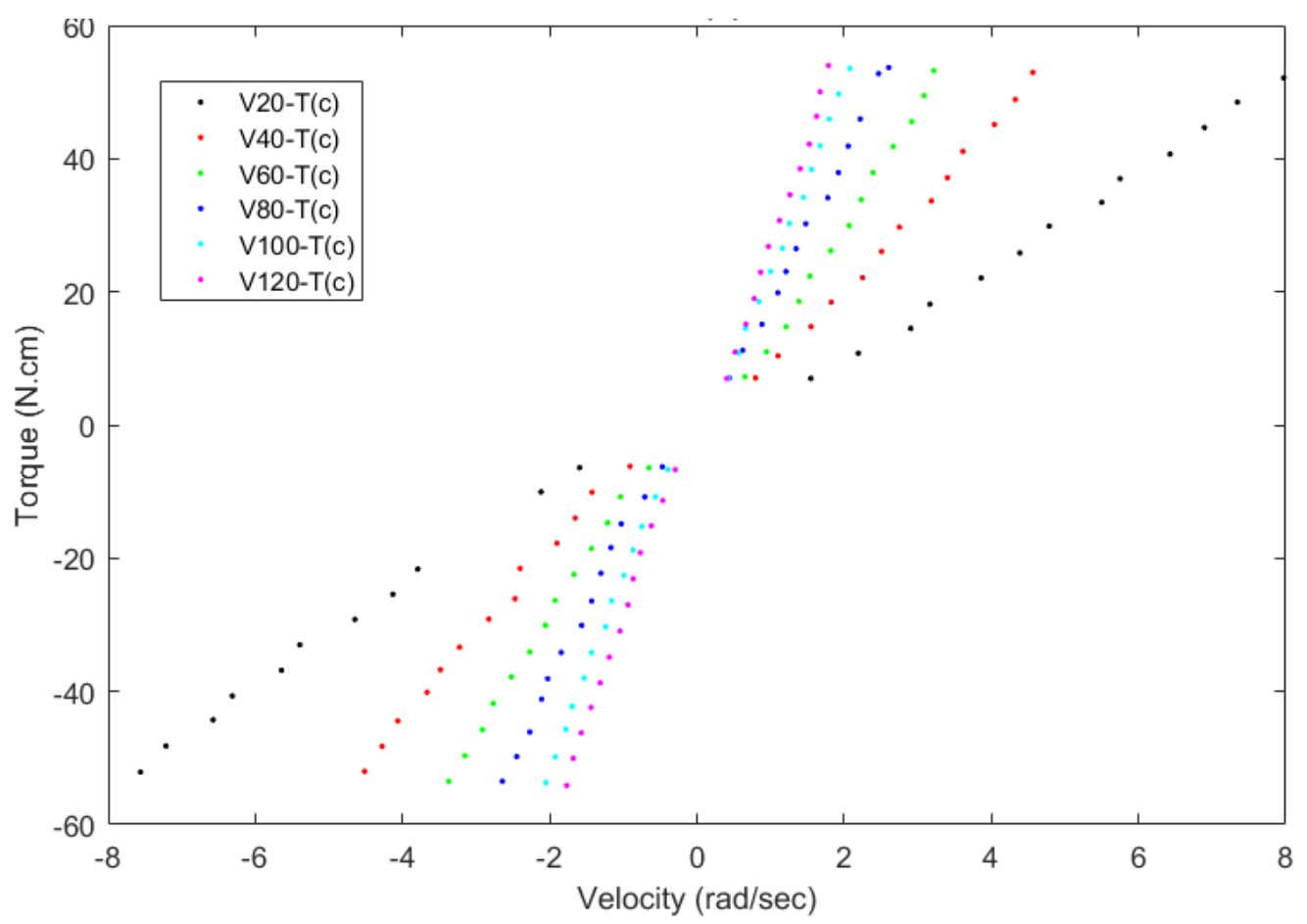

Figure 9 Relationship of velocity and damping torque $\left(T_{\text {dampingD }}\right)$

\begin{tabular}{ccc}
\hline Gain & \multicolumn{1}{c}{ CCW } & CW \\
\hline 20 & $F(t)=45.24 \dot{y}(t)-5.154$ & $F(t)=47.57 \dot{y}(t)+6.228$ \\
40 & $F(t)=76.4 \dot{y}(t)-3.622$ & $F(t)=77.57 \dot{y}(t)-1.933$ \\
60 & $F(t)=112.7 \dot{y}(t)-5.911$ & $F(t)=105.6 \dot{y}(t)-1.909$ \\
80 & $F(t)=139 \dot{y}(t)-3.407$ & $F(t)=133.4 \dot{y}(t)-2.571$ \\
100 & $F(t)=176.9 \dot{y}(t)-4.949$ & $F(t)=169.9 \dot{y}(t)-2.925$ \\
120 & $F(t)=206.5 \dot{y}(t)-6.294$ & $F(t)=191.2 \dot{y}(t)-4.143$
\end{tabular}

340 As this PTO simulation platform is designed to work in real time in labs, therefore, gain-coefficient 341 relationship curves are also drawn for generic use, in which the $\varsigma_{P}$ value in each fitted equations is 342 used as the linear damping coefficient. And they are shown in Fig.10, the blue lines stand for the Dc 343 and Gain relationship in a counterclockwise, and red lines in clockwise. Solid lines are using $T_{\text {dampings }}$ 344 as the damping torque, while dotted lines using $T_{\text {damping } D}$. 


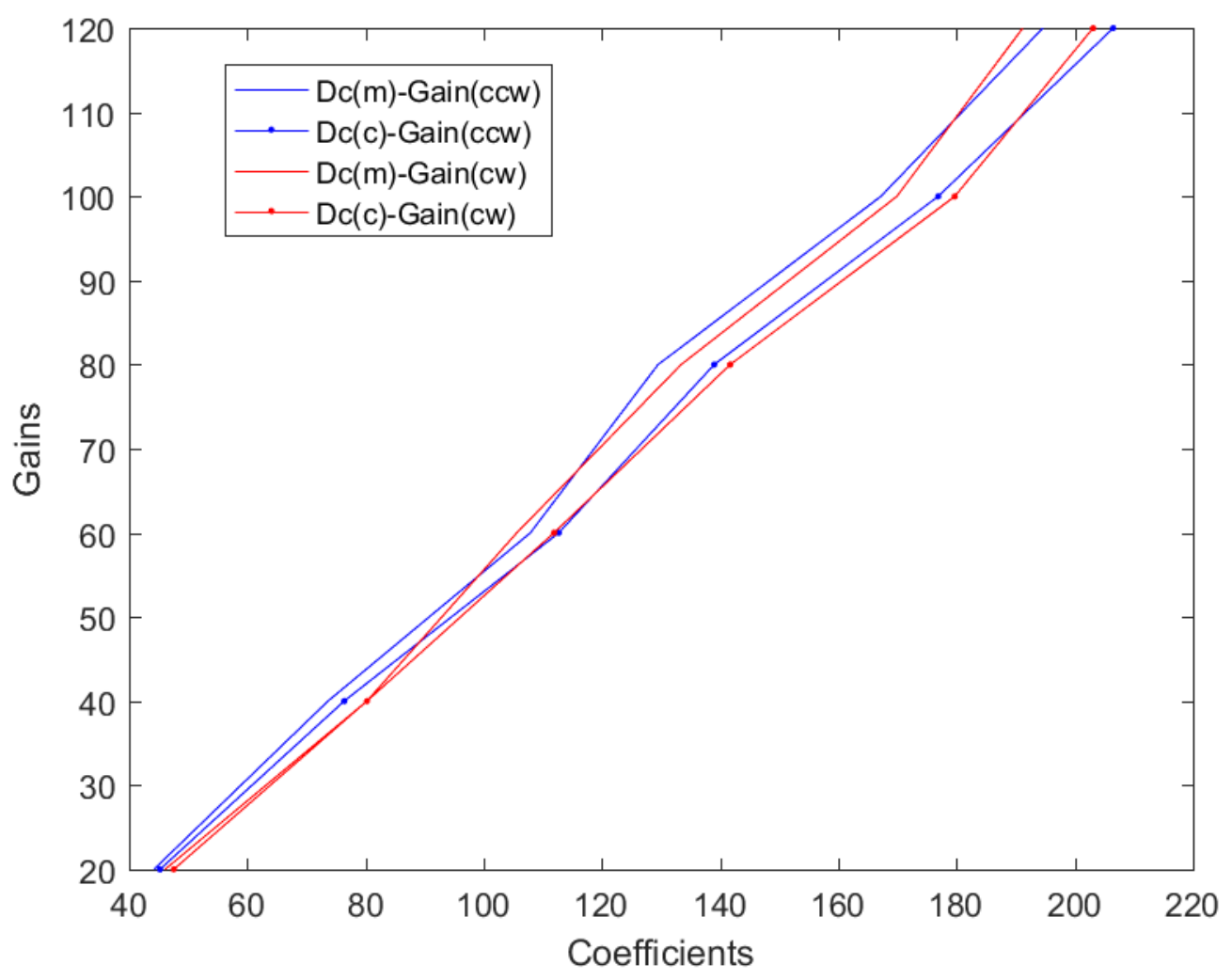

Figure 10 Relationship of input gains and linear damping force coefficients

With the quadratic control function in the software in the loop, the relationship between velocity ( $\mathrm{V}$ ) and the damping torque $T_{\text {dampings }}$ could be drawn as shown in Fig.11. On the left of Fig.11, the star points are formed of the data from drop tests in CCW direction, and on the right are composed of the data from drop tests in CW direction. As shown in Fig.11, it is learned that the quadratic relationship of the produced damping and the trigger velocity is achieved the trigger velocity should be the rotate/pitch velocity of the wave energy converter devices when using the platform in tank testing. For different five gains, the PTO simulation platform is showed to be able to produce different quadratic PTO damping. Similarly, the essential fitting tool is also used to draw the quadratic equations, as listed in Table 6. 
(a)

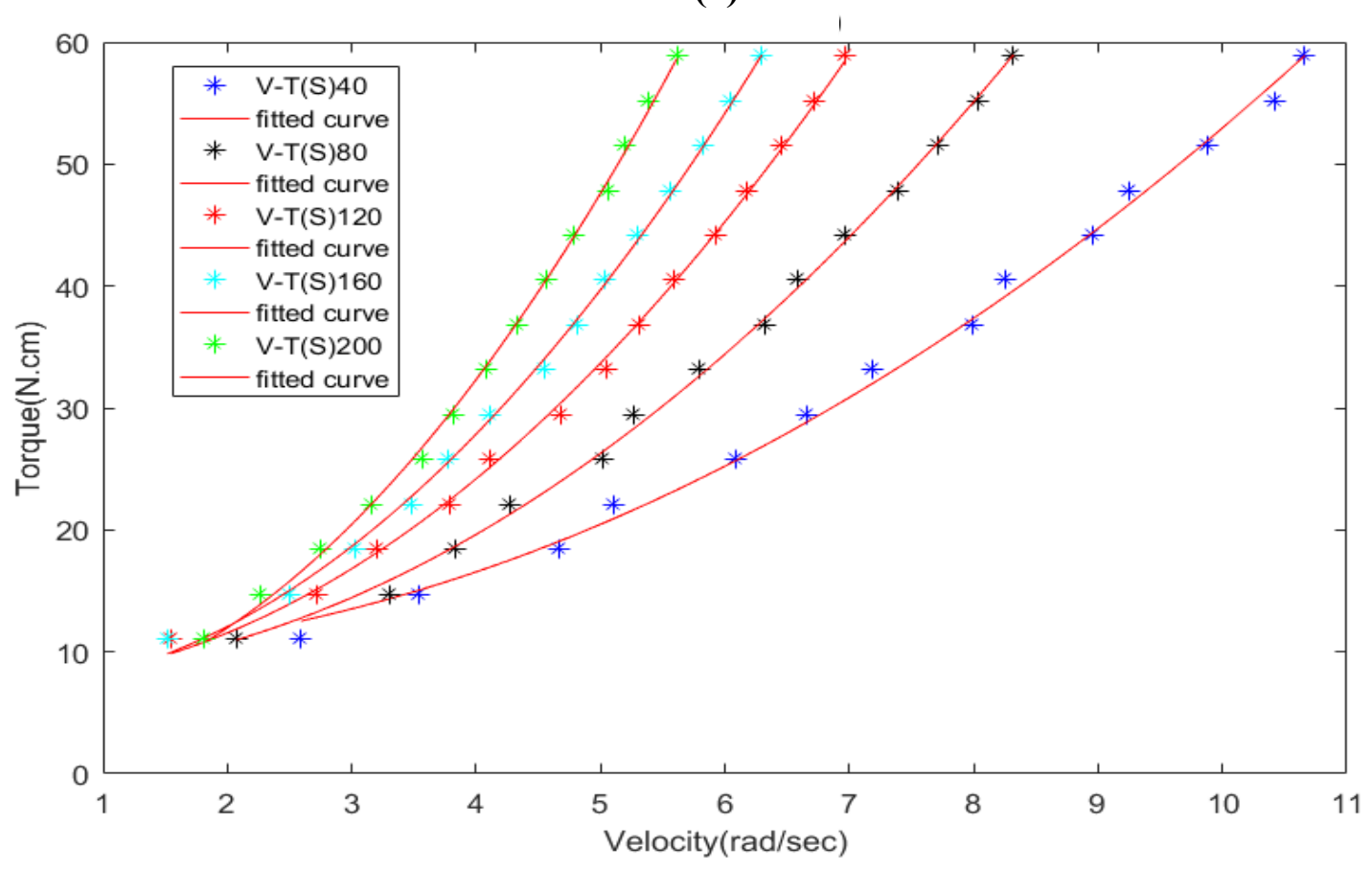

(b)

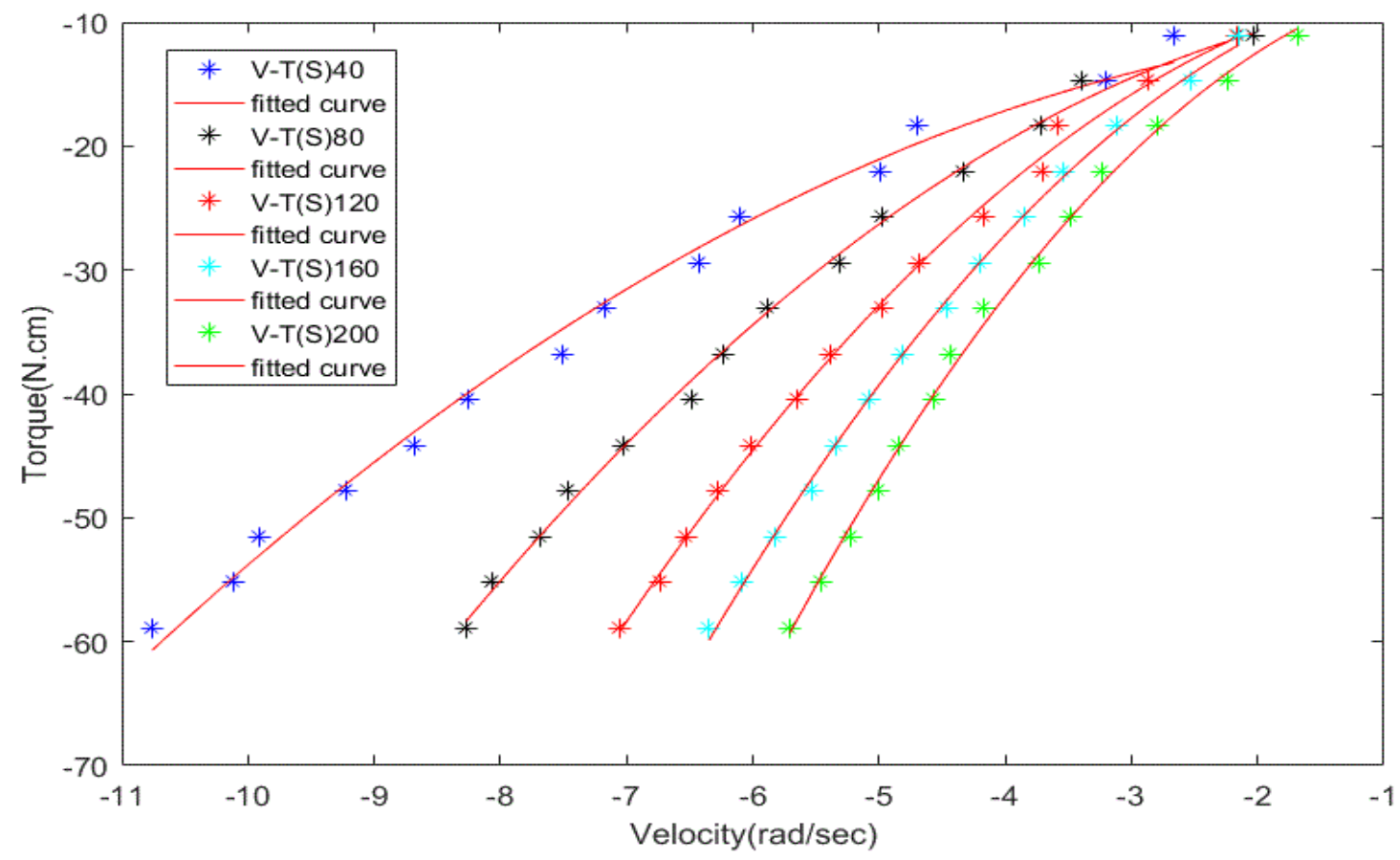

Figure 11 Relationship of velocity and damping torque( $\left.T_{\text {dampings }}\right)($ left is the curves for tests drop in CCW direction; right is 371 the curves for tests fall in CW direction)

372 As gain increases the radians of the quadratic open arc increases which represents a larger quadratic 373 damping coefficient. The damping coefficient $\varsigma_{P}$ can be derived from the fitted equation in Table 6 .

374 The fit equations are in the form of $F(t)=\varsigma_{P} \times \dot{y}(t)^{2}+u$, likewise, the $u$ is also the uncertainty for 375 quadratic PTO simulation discussed below in section 5 . In this study, five different gain values for 
nonlinear damping cases were examined, and the damping coefficients were measured at gain $=40$, $80,120,160,200$, with the corresponding damping ratios $\varsigma_{P}=17.11,29.18,41.6,51.93,66.98$, in counter clockwise direction and $\varsigma_{P}=-17.24,-29.15,-42,-53.21,-64.81$, respectively as shown in Table 6.

Table 6 Table of drawn functions based on $T_{\text {dampingS }}$ for nonlinear PTO

\begin{tabular}{ccc}
\hline Gain & \multicolumn{2}{c}{ CCW } \\
\hline & & CW \\
40 & $F(t)=17.11 \dot{y}(t)^{2}+9.619$ & $F(t)=-17.24 \dot{y}(t)^{2}-10.16$ \\
80 & $F(t)=29.18 \dot{y}(t)^{2}+7.799$ & $F(t)=-29.15 \dot{y}(t)^{2}-7.843$ \\
120 & $F(t)=41.6 \dot{y}(t)^{2}+7.334$ & $F(t)=-42 \dot{y}(t)^{2}-6.254$ \\
160 & $F(t)=51.93 \dot{y}(t)^{2}+6.809$ & $F(t)=-53.21 \dot{y}(t)^{2}-5.602$ \\
200 & $F(t)=66.98 \dot{y}(t)^{2}+5.182$ & $F(t)=-64.81 \dot{y}(t)^{2}-5.851$ \\
\hline
\end{tabular}

381

382 Similarly, for quadratic PTO damping, when the $T_{\text {dampingD }}$ is directly used to give a prediction of PTO 383 damping in real time testing. Uncertainty is also introduced, learn from the relationship curves 384 between $T_{\text {damping } D}$ and real-time velocities in Fig.12, the quadratic relationships are reduplicated, and 385 the uncertainty could also be reflected in the $\varsigma_{P}$ in the fitted equations. The fitted equations are listed 386 in Table 7. And the corresponding damping ratios $\varsigma_{P}=17.59,30.48,43.22,52.42,66.99$, in 387 counterclockwise direction and $\varsigma_{P}=-17.66,-30.54,-43.78,-55.19,-67.87$, respectively. 


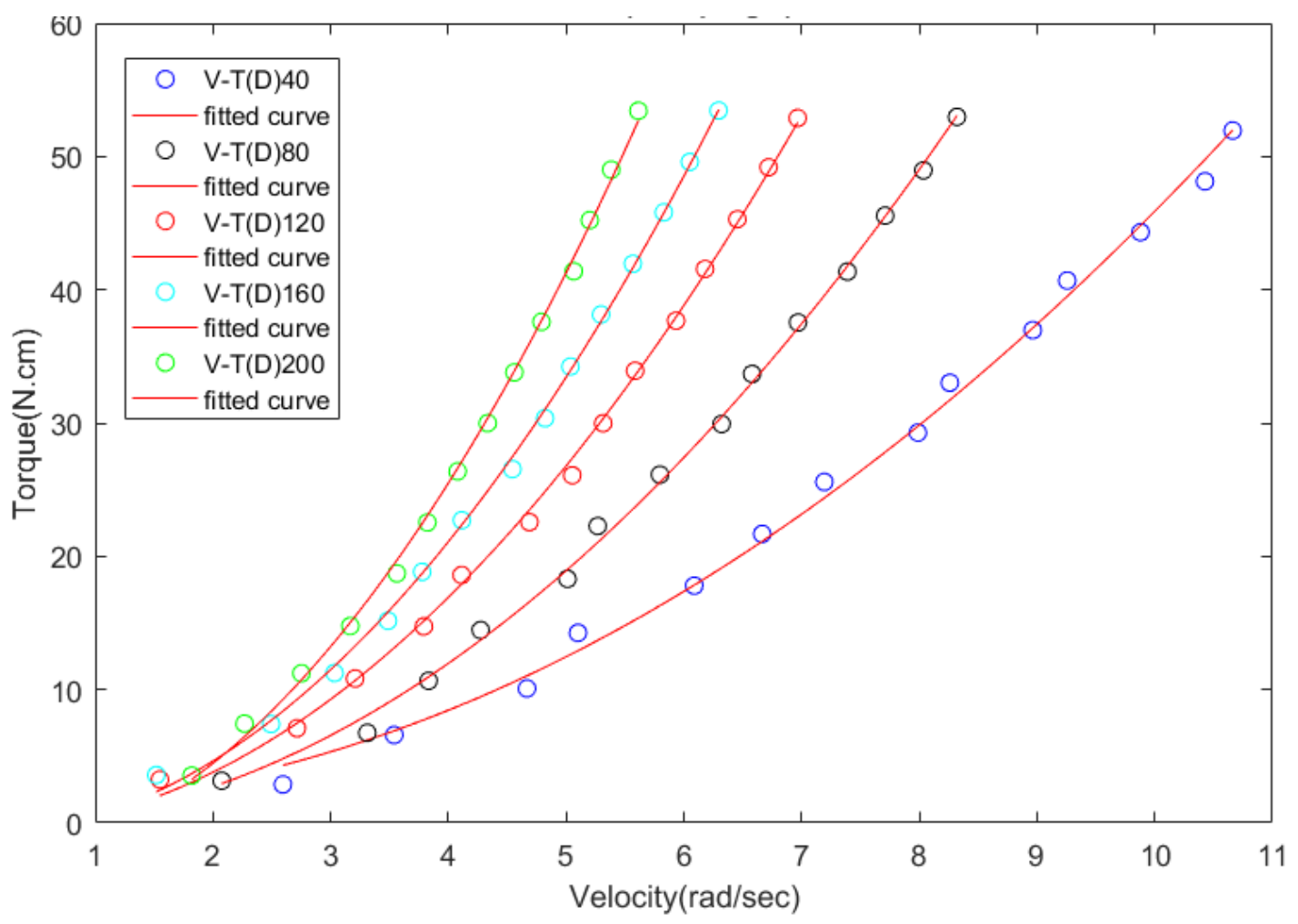

(b)

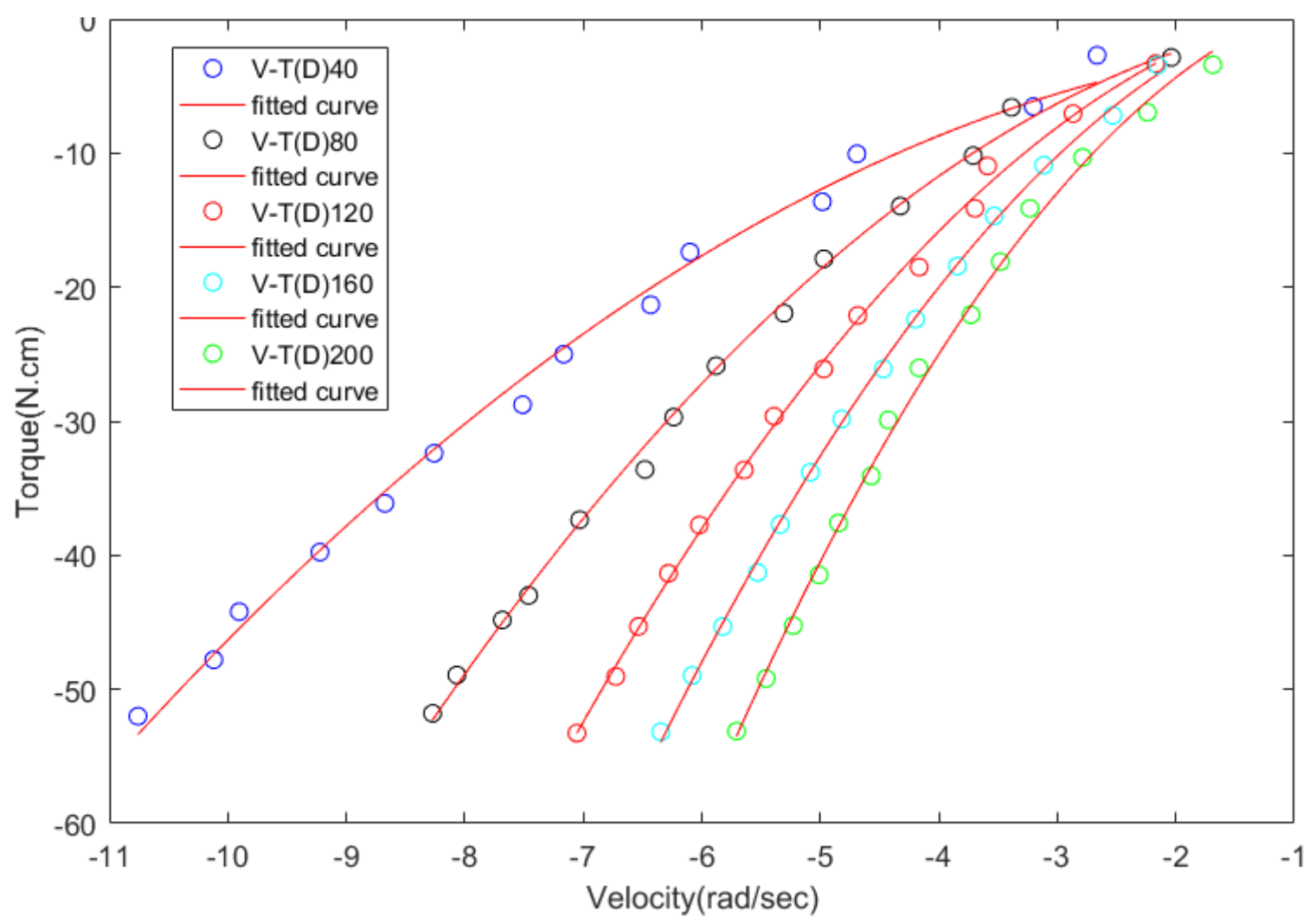

392 Figure 12 Relationship of velocity and damping torque $\left(T_{\text {dampingD }}\right)$ (a.is the curves for tests drop in CCW direction; b.is the curves for tests drop in CW direction) 


\begin{tabular}{ccc}
\hline Gain & \multicolumn{2}{c}{ CCW } \\
\hline & & CW \\
40 & $F(t)=17.59 \dot{y}(t)^{2}+1.323$ & $F(t)=-17.68 \dot{y}(t)^{2}-1.539$ \\
80 & $F(t)=30.48 \dot{y}(t)^{2}-0.3805$ & $F(t)=-30.54 \dot{y}(t)^{2}+0.6612$ \\
120 & $F(t)=43.22 \dot{y}(t)^{2}-0.583$ & $F(t)=-43.78 \dot{y}(t)^{2}+1.913$ \\
160 & $F(t)=52.42 \dot{y}(t)^{2}-0.8192$ & $F(t)=-55.19 \dot{y}(t)^{2}+2.362$ \\
200 & $F(t)=66.99 \dot{y}(t)^{2}-2.54$ & $F(t)=-67.87 \dot{y}(t)^{2}+2.511$
\end{tabular}

396

And the quadratic coefficients are used as the non-linear damping coefficients to acquire the Dc-Gain curves, as shown in Fig.13, in which, the two solid lines are based on $T_{\text {dampings }}$, and the other two dotted lines are related to $T_{\text {damping } D}$. The blue ones are in CCW direction and red lines in CW direction.

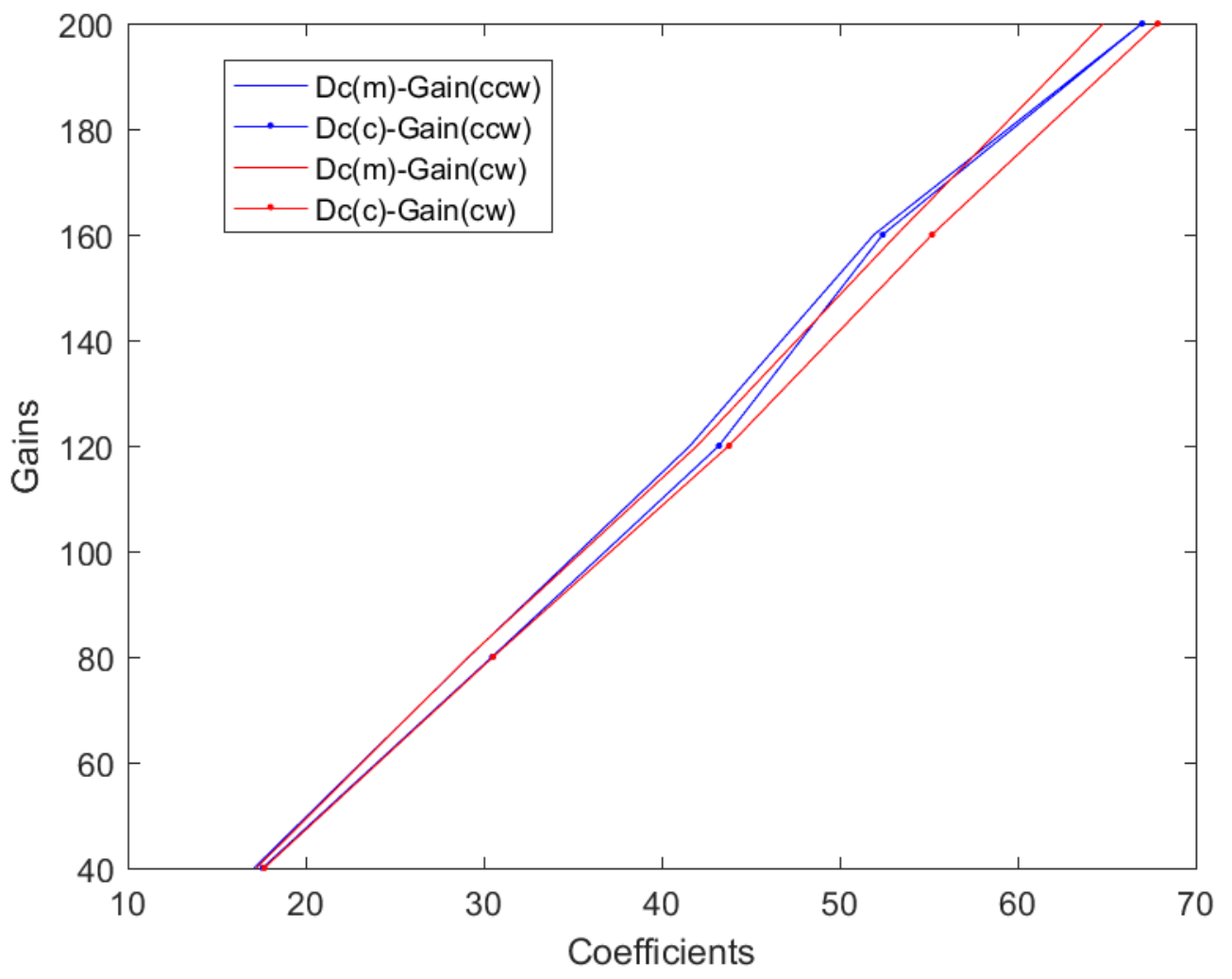

400

Figure 13 Correlation between input gains and coefficients of quadratic damping force

402 
It is noted that a large proportion of research about Wave Energy devices did not include an uncertainty analysis of their experiments. As pointed out by Lamont-Kane et al. [39], physical tests suffer from errors compared to the actual value of the quantity of interest because physical tests and measurements may not be wholly repeatable and reproducible. Without considering the uncertainties, one may get different results from each testing even with the same facilities and model. Therefore, it is more meaningful to give a range that contains the measured result and say the real value will fall into that range instead of providing a single value. And the qualitative and quantitative analysis of the range caused by lack of knowledge is called uncertainty analysis.

$Y=y \pm U$

Where the $Y$ is the measurand, that is the value of the particular quantity to be measured. $y$ is the estimated value of the measurand, and the $U$ is the expanded uncertainty defined as

$417 U=k \times u_{c}(y)$

where the $k$ is the coverage factor decided by the level of confidence needed. The $u_{c}(y)$ is the combined standard uncertainty which is calculated based on standard uncertainty. Judging by the two components in Equation(6), the expanded uncertainty can be interpreted as a combined standard uncertainty with a level of confidence. Hence, the $k$ can be explained as (assuming the level of confidence is $95 \%$ here) there is $95 \%$ chance that the simulated PTO damping $Y$ is $y-U \leq Y \leq y+U$

where the expanded uncertainty is within $\pm u$ for simulated PTO and independent on time as shown in Table 8.

Table 8 Comparison of difference between the targeted and fitted equations

\begin{tabular}{|c|c|c|c|c|}
\hline & Control function( & \multicolumn{2}{|c|}{ Fitted equation $(y)$} & $U$ \\
\hline \multirow[t]{7}{*}{$n=1$} & $F(t)=\varsigma_{P} \times \dot{y}(t)$ & $F(t)=\varsigma_{P} \times \dot{y}(t)+u$ & $F(t)=\varsigma_{P} \times \dot{y}(t)+u$ & $\pm u$ \\
\hline & & $F(\mathrm{t})=44.22 \dot{y}(t)+2.834$ & $F(t)=46.12 \dot{y}(t)-2.425$ & \pm 2.834 \\
\hline & & $F(t)=73.66 \dot{y}(t)+4.585$ & $F(t)=77.57 \dot{y}(t)-1.933$ & \pm 4.585 \\
\hline & & $F(t)=107.9 \dot{y}(t)+2.277$ & $F(t)=105.6 \dot{y}(t)-1.909$ & \pm 2.277 \\
\hline & & $F(t)=129.5 \dot{y}(t)+4.934$ & $F(t)=133.4 \dot{y}(t)-2.571$ & \pm 4.934 \\
\hline & & $F(t)=167.2 \dot{y}(t)+3.445$ & $F(t)=169.9 \dot{y}(t)-2.925$ & \pm 3.445 \\
\hline & & $F(t)=194.6 \dot{y}(t)+2.003$ & $F(t)=191.2 \dot{y}(t)-4.143$ & \pm 4.143 \\
\hline \multirow[t]{2}{*}{$n=2$} & $F(t)=\varsigma_{P} \times \dot{y}(t)^{2}$ & $F(t)=\varsigma_{P} \times \dot{y}(t)^{2}+u$ & $F(t)=\varsigma_{P} \times \dot{y}(t)^{2}-u$ & $\pm u$ \\
\hline & & $F(t)=17.11 \dot{y}(t)^{2}+9.619$ & $F(t)=-17.24 \dot{y}(t)^{2}-10.16$ & \pm 10.16 \\
\hline
\end{tabular}




$$
\begin{array}{ccc}
F(t)=29.18 \dot{y}(t)^{2}+7.799 & F(t)=-29.15 \dot{y}(t)^{2}-7.843 & \pm 7.843 \\
F(t)=41.6 \dot{y}(t)^{2}+7.334 & F(t)=-42 \dot{y}(t)^{2}-6.254 & \pm 7.334 \\
F(t)=51.93 \dot{y}(t)^{2}+6.809 & F(t)=-53.21 \dot{y}(t)^{2}-5.602 & \pm 6.809 \\
F(t)=66.98 \dot{y}(t)^{2}+5.182 & F(t)=-64.81 \dot{y}(t)^{2}-5.851 & \pm 5.851
\end{array}
$$

$\begin{array}{ll}\mathrm{U} & +9.619-10.16\end{array}$

428

429

430

431

432

433

434

435

436

437

438

439

440

441

442

443

444

445

446

447

448

449

450

451

452

453

It is found that the uncertainty in the measurement, components, and methodology leads to an uncertainty of the PTO simulation with the bias of \pm 10.16 . When the platform is given an input gain, a linear or quadratic corresponding PTO damping force could be produced, and the function of the produced damping is no more far from the control function predefined in the software by a constant bias within \pm 10.16 . The uncertainty of the PTO simulation platform in this section includes three main parts, in section5.1, the change in the measurement is calculated based on data of repeated drop tests; section 5.2 presents the uncertainty from components of the platform, and in section 5.3 we analyse the uncertainty of the methodology of using current measurement $\left(T_{\text {dampingD }}\right)$ to give prediction on the physical damping torque ( $\left.T_{\text {dampings }}\right)$.

\subsection{Uncertainty in measurement}

Evaluation of a component of standard uncertainty is a method for the assessment of uncertainty by the statistical analysis of series repeated observations. For a measurand $\mathrm{Y}$ that is measured by $\mathrm{N}$ independent repeated observations $y_{k}$, the best-estimated value is the arithmetic mean of the $\mathrm{N}$ observations:

$\bar{y}=\frac{1}{N} \sum_{k=1}^{N} y_{k}$

The variance of the comments is given by

$s^{2}(y)=\frac{1}{N} \sum_{j=1}^{N}\left(y_{j}-\bar{y}\right)^{2}$

And the deviation of the mean is granted by

$s(y)=\sqrt{s^{2}(y)}=\sqrt{\frac{1}{N} \sum_{j=1}^{N}\left(y_{j}-\bar{y}\right)^{2}}$

Assume standard uncertainty merely is the positive square root of the difference of the mean and is expressed as

$u(y)=s(y)$

Then the change in measurement can be described as the observation/calculation of the standard deviation of the measures, as shown in Fig. 14 and Fig. 15. 

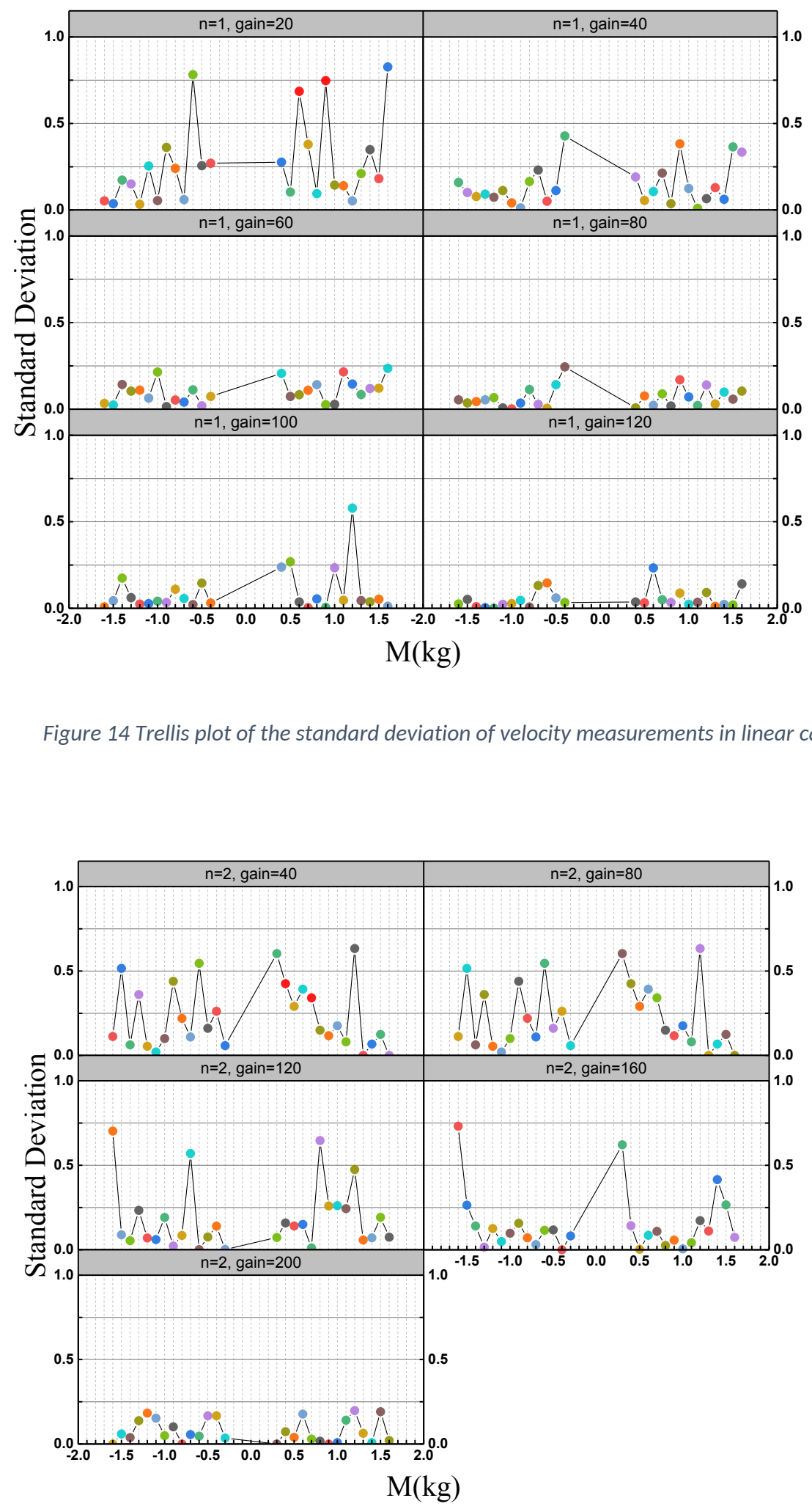
460 Uncertainty in components is also the main source of uncertainties for the innovative PTO simulation 461 platform. This uncertainty is usually obtained by a) Experience with or general knowledge of the 462 behaviour and properties of relevant materials and instruments; b) Manufacturer's specifications; $c$ ) 463 Data provided in calibration and other certificates; d) Uncertainty assigned to reference data taken 464 from handbooks. An uncertainty in components adopted in our experiments is given in Table 9.

465 The raw data obtained from the data acquisition system for one standardized drop test is shown in 466 Fig.5. The data we collected from the current sensor and tachometer are voltages, so we need to make 467 a unit conversion before output, as the resolution of the current sensor is $10 \mathrm{~A} / 75 \mathrm{mV}$, we use a unit 468 conversion coefficient 333.33 added to the voltage, in order to output the signals from current sensor 469 in Amp, making it 133.33A/volt. The resolution of the tachometer is $333.333 \mathrm{rpm} / \mathrm{volt}$. Thus, 470 calculations show that unit for current signals output in Spike (which is the software interface with the 471 DAQ) is Amp, and for tachometer signals is rpm. Then the data in the unit of rpm and amp is sampled 472 into excel, then input into MATLAB for plotting.

Table 9 Properties of critical components

\begin{tabular}{|c|c|c|c|c|}
\hline $\begin{array}{l}\text { Meaningful } \\
\text { parameters }\end{array}$ & Component & $\begin{array}{l}\text { Data from } \\
\text { sheet }\end{array}$ & Uncertainty source & Uncertainty \\
\hline $\begin{array}{l}\text { Damping } \\
\text { constant }\end{array}$ & Motor & $17 \mathrm{~N} \mathrm{~cm} / \mathrm{A}$ & $\begin{array}{l}\text { Nominal value from the } \\
\text { manufacturer } \\
\text { (temperature dependent) }\end{array}$ & $+/-0.1 \mathrm{Ncm} / \mathrm{A}$ \\
\hline $\begin{array}{l}\text { Velocity } \\
\text { measurements }\end{array}$ & Tachometer & 3V/1000rpm & $\begin{array}{l}\text { Typical analogue tacho } \\
\text { linearity. }\end{array}$ & $+/-1 \%$ \\
\hline $\begin{array}{l}\text { Current } \\
\text { Measurements }\end{array}$ & $\begin{array}{l}\text { Current } \\
\text { Shunt }\end{array}$ & $\begin{array}{l} \pm 1.4 \% \text { Gain } \\
\text { Error, } 0.3 \mu \\
V /{ }^{\circ} \mathrm{C} \text { Offset } \\
\text { Drift } 0.005 \% /{ }^{\circ} \mathrm{C} \\
\text { Gain Drift (Max) } \\
\text { linearity }\end{array}$ & $\begin{array}{l}\text { From manufacturers' } \\
\text { Datasheet }\end{array}$ & $+/-1.4 \%$ \\
\hline $\begin{array}{l}\text { Current } \\
\text { measurements }\end{array}$ & $\begin{array}{l}\text { Current } \\
\text { shunt } \\
\text { monitor }\end{array}$ & & $\begin{array}{l}\text { From manufacturers } \\
\text { datasheet }\end{array}$ & $+/-0.1 \%$ \\
\hline Offset & Amplifier & $\begin{array}{l}\text { Manually } \\
\text { adjusted to } \\
\text { zero to within } \\
+/-0.01 \text { volt. }\end{array}$ & $\begin{array}{l}\text { Unbalance in zero } \\
\text { calibration }\end{array}$ & $\begin{array}{l}\text { Result in the } \\
\text { unbalance } \\
\text { between } \\
\text { simulated PTOs in } \\
\text { CCW and CW } \\
\text { directions }\end{array}$ \\
\hline Linearity & Amplifier & $+/-0.25 \%$ & & \\
\hline Current rating & Amplifier & $\begin{array}{l}\text { 2A continuous/ } \\
10 \mathrm{~A} \text { peak (for } 1 \\
\text { second) }\end{array}$ & $\begin{array}{l}\text { When the current exceeds, } \\
\text { rated current amplifier } \\
\text { output current is reduced. }\end{array}$ & $\begin{array}{l}\text { Limit drop } \\
\text { weights so that } \\
\text { amplifier } \\
\text { operates within } \\
\text { current rating. }\end{array}$ \\
\hline Power rating & Amplifier & $\begin{array}{l}48 \mathrm{~W} \\
\text { continuous/240 } \\
\text { W peak(for } 1 \\
\text { second) }\end{array}$ & $\begin{array}{l}\text { When power exceeds, } \\
\text { rated amplifier output } \\
\text { power is reduced. }\end{array}$ & $\begin{array}{l}\text { Limit drop } \\
\text { weights so that } \\
\text { amplifier } \\
\text { operates within } \\
\text { power rating. }\end{array}$ \\
\hline
\end{tabular}




\section{Data}

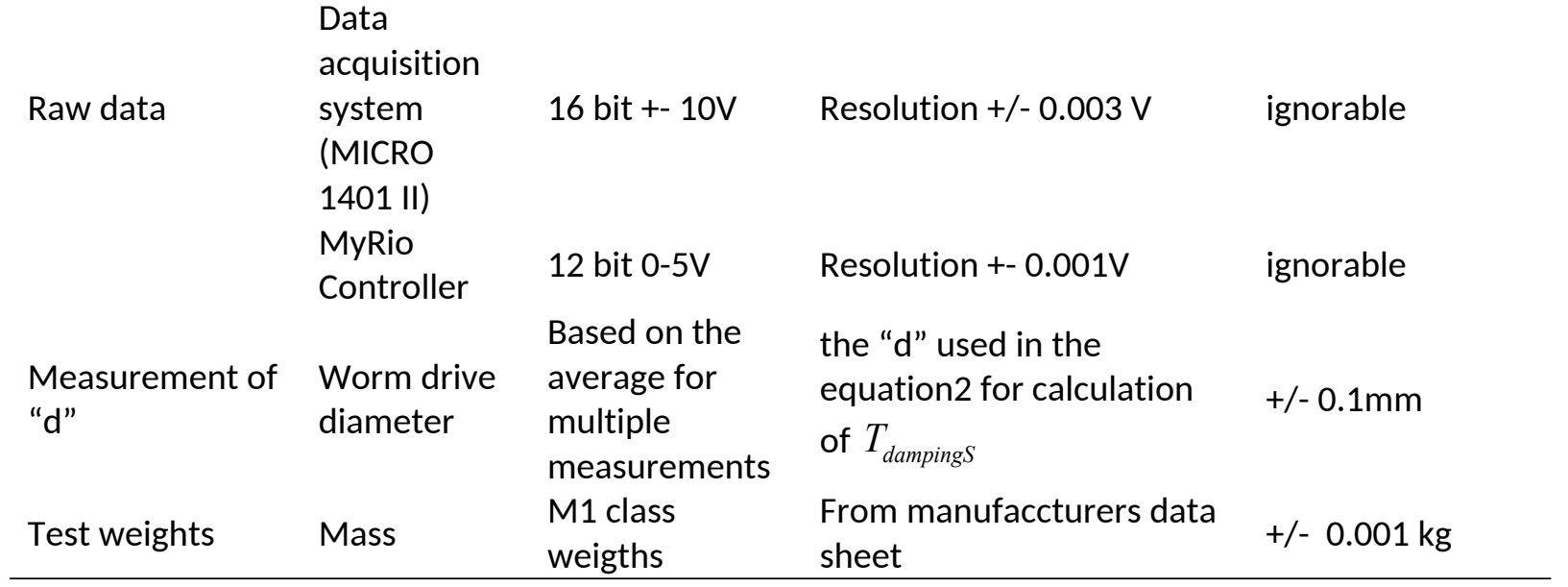

\subsection{Uncertainty in methodology}

477 The uncertainty of the methodology of using current measurement $\left(T_{\text {dampingD }}\right)$ to give a prediction on 478 the physical damping torque ( $\left.T_{\text {dampings }}\right)$.

479 Because for DC motors and generators, it is concluded that the torque produced by motor proportion 480 to the current flows through the motor, which is described as

$481 T=k_{T} \times I$

482 Where $k_{T}$ is the constant coefficient of motors, therefore it is designed to measure the dynamic 483 damping torque by measuring the current of the damping motor. However, there is an absolute 484 uncertainty of using current measurement to predict the physical damping torque. Therefore, 485 comparisons between two damping torques for both linear PTO and nonlinear PTO is presented in 486 Fig.16, where black data represents the data for counterclockwise and red for clockwise. We can draw 487 a rough inference that $T_{\text {dampingD }}$ is precisely proportional to $T_{\text {dampingS }}$, and the proportion coefficient is reasonably close to 1 , so $T_{\text {dampingD }}$ can be a prediction of $T_{\text {dampings }}$ when simulating a dynamic PTO. 


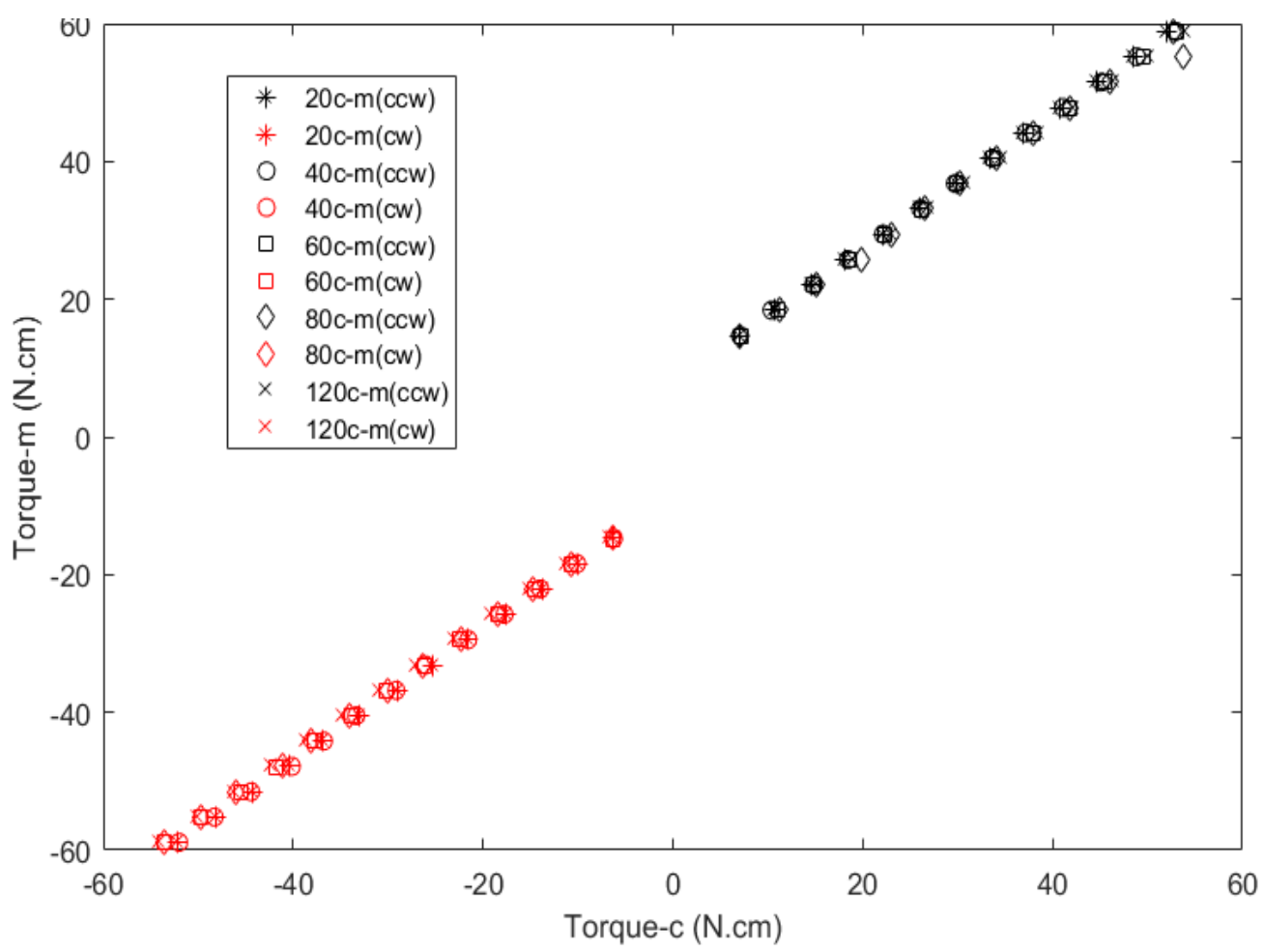

490

491

492

(b)

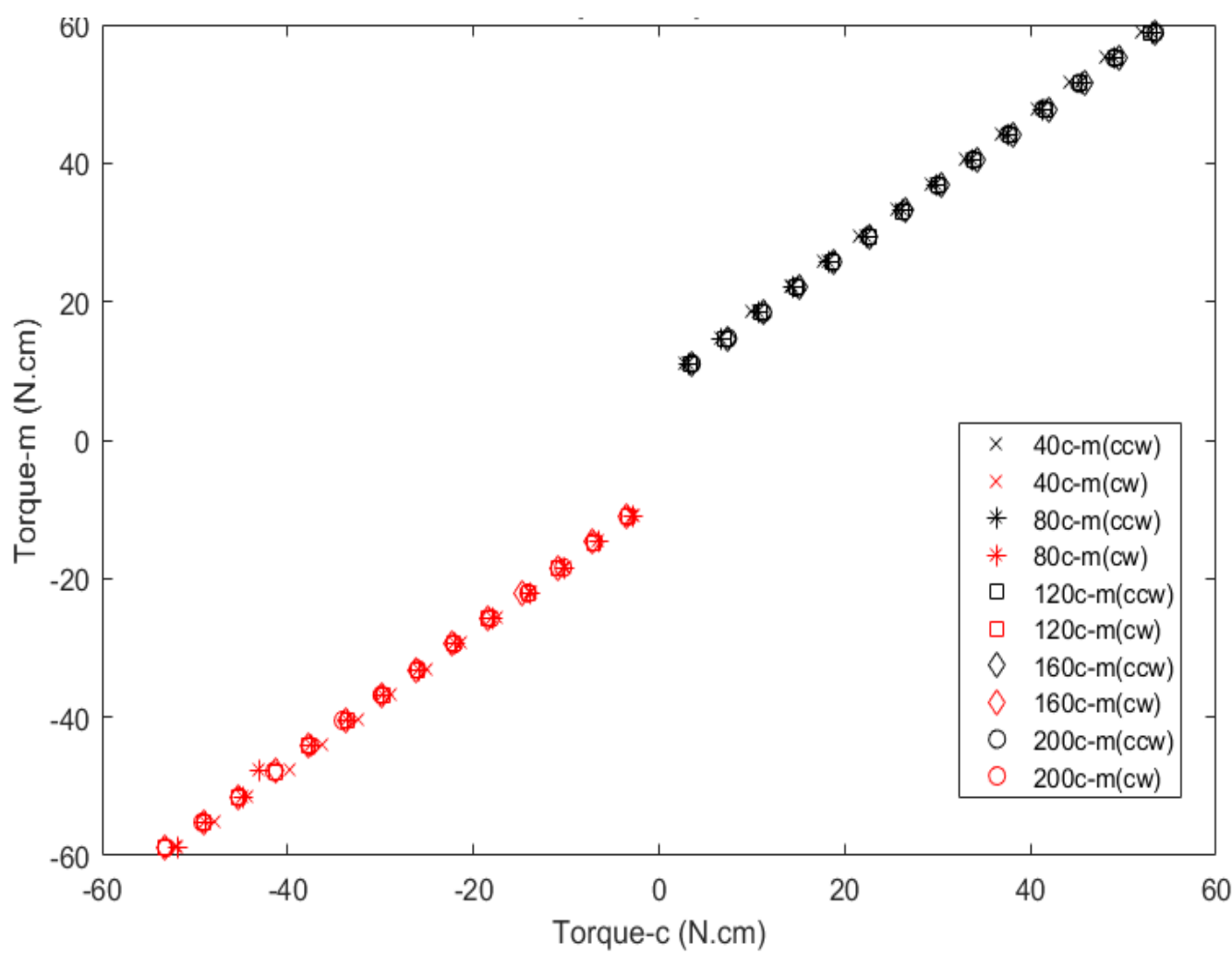




\subsection{Future work}

The control function (equation 3) used in this paper, is a direct expression of the aimed damping forces (linear or quadratic). As for the uncertainty provided above, the iteration method presented in [40] will be used to adjusting damping spectrum to achieve a given value of correlation coefficient between the damping spectrum and the target one. Moreover, varying damping in traditional vibration systems in [41] and fractional vibrations reported in $[42,43]$ may be useful for the future work to possibly explore the mechanism of varying damping in the ocean energy converters described in this manuscript.

\section{Conclusions}

A novel experimental PTO simulation platform was proposed by using software-in-loop simulation methodology. The working principle is original, and the method of how to build up a PTO simulation platform is introduced in great details. A large number of drop tests are performed to calibrate the platform, and the following conclusions were drawn:

1. This PTO simulation platform can produce linear PTO damping and nonlinear damping in a wide range (quadratic damping is taken as a simple nonlinear example);

2. Reasonable correlation curves between the input gains of the PTO simulation platform and the coefficients of simulated PTO damping forces are achieved for both linear and quadratic cases.

3. The correlation indicates the PTO simulation platform's capacity of simulating linear PTO can reach 40-220 and can reach 10-70 for quadratic damping regarding damping force coefficient.

4. Dynamic torque measurement is adopted to predict the dynamic damping torque in dynamic tank testing which causes a tiny uncertainty in methodology, and the possibility is quantitatively analysed;

5. Gain-Damping coefficient curves are drawn and able to be used as a reference to simulate customer-suited PTO damping

\section{Acknowledgement}

The authors acknowledge the China Scholarship Council (File No.201606320223) and University of Strathclyde Research Studentship for their financially supporting Xue Jiang's PhD research. The support from the hydrodynamic lab of the University of Strathclyde is also highly appreciated.

\section{Reference}

1. Magagna, D. and A. Uihlein, 2014 JRC Ocean Energy Status Report. European Commission Joint Research Centre, 2015.

2. Salvatore, J., World Energy Perspective: Cost of Energy Technologies. World Energy Council, 2013.

3. Hayward, J., et al., Economic modelling of the potential of wave energy. Renewable Energy, 2012. 48: p. 238-250.

4. Short, W., D.J. Packey, and T. Holt, A manual for the economic evaluation of energy efficiency and renewable energy technologies. 1995, National Renewable Energy Lab., Golden, CO (United States).

5. Previsic, M., et al., The future potential of wave power in the United States. Prepared by ReVision Consulting on behalf of DOE, Denver, CO (US). http://www. re-vision. net/documents/The, 2012. 20. 
540 6. Dalton, G.J., R. Alcorn, and T. Lewis, Case study feasibility analysis of the Pelamis wave energy convertor in Ireland, Portugal and North America. Renewable Energy, 2010. 35(2): p. 443-455.

7. Drew, B., A.R. Plummer, and M.N. Sahinkaya, A review of wave energy converter technology. 2009, Sage Publications Sage UK: London, England.

8. Sykes, R.K., A.W. Lewis, and G. Thomas. A numerical and physical comparison of a geometrically simple fixed and floating oscillating water column. in ASME 2008 27th International Conference on Offshore Mechanics and Arctic Engineering. 2008. American Society of Mechanical Engineers.

9. Antonio, F.d.O., Wave energy utilization: A review of the technologies. Renewable and sustainable energy reviews, 2010. 14(3): p. 899-918.

10. Ames, F., Ocean wave energy converter. 1980, Google Patents.

11. Ames, P.F., Ocean wave energy converter. 1987, Google Patents.

12. Woodbridge, D.D., Wave operated electrical generation system. 1981, Google Patents.

13. Jacobi, E.F. and R.J. Winkler, Wave motion electric generator. 1983, Google Patents.

14. Neuenschwander, V.L., Wave activated generator. 1985, Google Patents.

15. Rich, A.H., Oceanographic generator. 1970, Google Patents.

16. Alamian, R., et al., Evaluation of technologies for harvesting wave energy in Caspian Sea. Renewable and Sustainable Energy Reviews, 2014. 32: p. 468-476.

17. Falnes, J., Optimum control of oscillation of wave-energy converters. International Journal of Offshore and Polar Engineering, 2002. 12(02).

18. Taylor, G.W. and D.B. Stewart, Wave energy converters (WECs) with linear electric generators (LEGs). 2008, Google Patents.

19. Sabol, T. and D.B. Stewart, Wave energy converters (WECS) with velocity multiplication. 2007, Google Patents.

20. Beels, C., et al., Application of the time-dependent mild-slope equations for the simulation of wake effects in the lee of a farm of Wave Dragon wave energy converters. Renewable Energy, 2010. 35(8): p. 1644-1661.

21. IRENA_Ocean_Energy_report_2014. 2014, International Renewable Energy Agency.

22. Astariz, S. and G. Iglesias, The economics of wave energy: A review. Renewable and Sustainable Energy Reviews, 2015. 45: p. 397-408.

23. Rusu, L. and F. Onea, The performance of some state-of-the-art wave energy converters in locations with the worldwide highest wave power. Renewable and Sustainable Energy Reviews, 2017. 75: p. 1348-1362.

24. Babarit, A., et al., Investigation on the energy absorption performance of a fixed-bottom pressure-differential wave energy converter. Applied Ocean Research, 2017. 65: p. 90-101.

25. Henriques, J., et al., Testing and control of a power take-off system for an oscillating-watercolumn wave energy converter. Renewable Energy, 2016. 85: p. 714-724.

26. Hong, Y., et al., Review on electrical control strategies for wave energy converting systems. Renewable and Sustainable Energy Reviews, 2014. 31: p. 329-342.

27. Hals, J., J. Falnes, and T. Moan, A comparison of selected strategies for adaptive control of wave energy converters. Journal of Offshore Mechanics and Arctic Engineering, 2011. 133(3): p. 031101.

28. António, F.d.O., Phase control through load control of oscillating-body wave energy converters with hydraulic PTO system. Ocean Engineering, 2008. 35(3): p. 358-366.

29. Forehand, D.I., et al., A fully coupled wave-to-wire model of an array of wave energy converters. IEEE Trans. Sustain. Energy, 2016. 7(1): p. 118-128.

30. Henderson, R., Design, simulation, and testing of a novel hydraulic power take-off system for the Pelamis wave energy converter. Renewable energy, 2006. 31(2): p. 271-283. 
31. Riley, P.F. and G.F. Riley. Next generation modeling III-agents: Spades---a distributed agent simulation environment with software-in-the-loop execution. in Proceedings of the 35th conference on Winter simulation: driving innovation. 2003. Winter Simulation Conference.

32. Battisti, T., G. Faruolo, and L. Magliocchetti. A State-of-the-Art SWIL (Software in the Loop) Electronic Warfare System Simulator for Performance Prediction and Validation. in International Workshop on Modelling and Simulation for Autonomous Systems. 2015. Springer.

33. Zang, Z., et al., Hydrodynamic responses and efficiency analyses of a heaving-buoy wave energy converter with PTO damping in regular and irregular waves. Renewable Energy, 2018. 116: p. 527-542.

34. Ekström, R., B. Ekergård, and M. Leijon, Electrical damping of linear generators for wave energy converters - A review. Renewable and Sustainable Energy Reviews, 2015. 42: p. 116128.

35. Wang, Z.L., Catch wave power in floating nets. Nature, 2017. 542(7640): p. 159.

36. Zhu, G., et al., Harvesting water wave energy by asymmetric screening of electrostatic charges on a nanostructured hydrophobic thin-film surface. ACS nano, 2014. 8(6): p. 60316037.

37. Su, Y., et al., Hybrid triboelectric nanogenerator for harvesting water wave energy and as a self-powered distress signal emitter. Nano Energy, 2014. 9: p. 186-195.

38. Chen, J., et al., Networks of triboelectric nanogenerators for harvesting water wave energy: a potential approach toward blue energy. ACS nano, 2015. 9(3): p. 3324-3331.

39. Lamont-Kane, P., M. Folley, and T. Whittaker. Investigating uncertainties in physical testing of wave energy converter arrays. in Proceedings, 10th European Wave and Tidal Energy Conference (EWTEC 2013), Aalborg, Denmark. 2013.

40. Li, M., An iteration method to adjusting random loading for a laboratory fatigue test. International Journal of Fatigue, 2005. 27(7): p. 783-789.

41. Piersol, A.G. and C.M. Harris, Harri's Shock and Vibration Handbook Fifth Edition. 2017: Mcgraw-hill.

42. Li, M., Three classes of fractional oscillators. Symmetry, 2018. 10(2): p. 40.

43. Li, M., Fractal time series-a tutorial review. Mathematical Problems in Engineering, 2010. 2010. 
621 List of equations

$622 \quad F_{\text {damping }}=$ weight $=m \times g$

623 (1)

$624 T_{\text {dampings }}=F_{\text {damping }} \times d / 2$

625 (2)

$626 \quad F(t)=\frac{\text { gain }}{100} \dot{y}(t)^{n}$

627

(3)

$628 \quad F(t)=\varsigma_{P} \times \dot{y}(t)^{n}$

629

630

(4)

631

$Y=y \pm U$

632

(5)

633

$U=k \times u_{c}(y)$

634

(6)

635

$y-U \leq Y \leq y+U$

636

637

638

639

640

641

642

643

644

645

646

647

648

649

650

651

652

653

654

655 


\section{List of tables}

657

658 Table 1 Selected gains for drop tests. .8

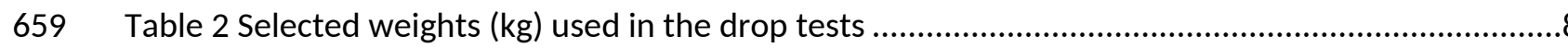

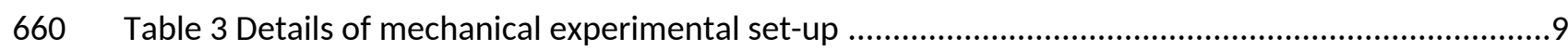

661 Table 4 Table of fitted functions based on $T_{\text {dampings }}$ for linear PTO ...................................................11

662 Table 5 Table of fitted functions based on $T_{\text {damping } D}$ for linear PTO ..................................................12

663 Table 6 Table of drawn functions based on $T_{\text {dampings }}$ for nonlinear PTO .............................................15

664 Table 7 Table of drawn functions based on $T_{\text {damping } D}$ for nonlinear PTO ............................................17

665 Table 8 Comparison of difference between the targeted and fitted equations................................18

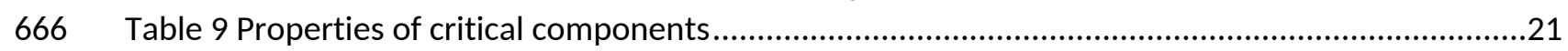




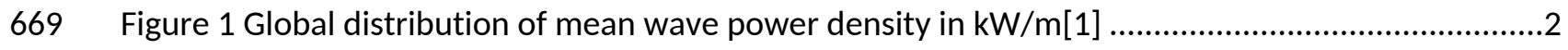

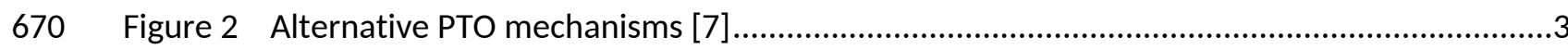

671 Figure 2 Ocean energy technology international Patent Cooperation Treaty publications between

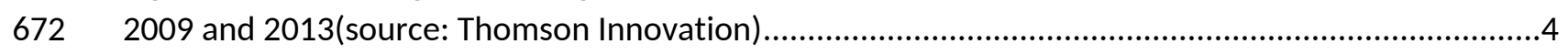

673 Figure 4 Schematic diagram of the loop for simulating the PTO damping ..........................................6

$674 \quad$ Figure $5 \mathrm{~A}$ typical drop test monitored by DAQ ............................................................................

675 Figure 6 Components of the PTO damping simulation platform .......................................................8

676 Figure 7 a)Schematic diagram of pretension in drop tests in counterclockwise, $f$ is the pre-tension

677 caused by " $m$ ", and $F_{\text {total }}$ is the driving force caused by " $M$ "; b) Mechanical model of drop .................9

678 Figure 8 Relationship of velocity and damping torque $\left(T_{\text {damping } S}\right)($ the points located in )...................10

679 Figure 9 Relationship of velocity and damping torque $\left(T_{\text {damping } D}\right)$..................................................12

680 Figure 10 Relationship of input gains and linear damping force coefficients......................................13

681 Figure 11 Relationship of velocity and damping torque $\left(T_{\text {dampings }}\right)($ left is the curves for tests drop in

682 CCW direction; right is the curves for tests fall in CW direction) ........................................................14

683 Figure 12 Relationship of velocity and damping torque $\left(T_{\text {dampingD }}\right.$ ) (a.is the curves for tests drop in

684 CCW direction; $b$.is the curves for tests drop in CW direction) .........................................................16

685 Figure 13 Correlation between input gains and coefficients of quadratic damping force ..................17

686 Figure 14 Trellis plot of the standard deviation of velocity measurements in linear cases .................20

687 Figure 15 Trellis plot of the standard deviation of velocity measurements in nonlinear instances.....20

688 Figure 16.a) for linear cases and b) for nonlinear cases ................................................................23 